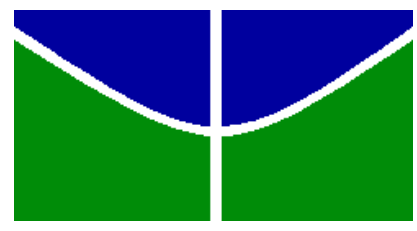

Universidade de Brasília

Faculdade de Economia, Administração, Contabilidade e Ciência da Informação e Documentação - FACE

Departamento de Economia

\author{
JOÃO RICARDO PEREIRA
}

Relações entre doações de campanha, denúncias de corrupção e variação de preço nas licitações de obras públicas

Brasília

Dezembro 2014 
Universidade de Brasília

Faculdade de Economia, Administração, Contabilidade e Ciência da Informação e Documentação - FACE

Departamento de Economia

\author{
JOÃO RICARDO PEREIRA
}

\title{
Relações entre doações de campanha, denúncias de corrupção e variação de preço nas licitações de obras públicas
}

\begin{abstract}
Dissertação de Mestrado apresentada ao Departamento Economia da Universidade de Brasília em 26/12/2014, como parte dos requisitos necessários à obtenção do título de Mestre em Economia.
\end{abstract}

Banca examinadora

Prof. Dr. Maurício Soares Bugarin (Orientador)

Prof $^{\mathrm{a}}$. Dr ${ }^{\mathrm{a}}$. Maria Eduarda Tannuri-Pianto (Membro)

Prof. Dr. Paulo Augusto P. de Britto (Membro)

Brasília

Dezembro 2014 


\section{Dedicatória}

Dedico este trabalho à minha esposa, que pelo exemplo, tanto tem me ensinado sobre o amor e sobre os mais altos valores morais no curso de nossa convivência diária. Dedico ainda à minha filha Mariana que vem encher de amor o nosso lar. 


\section{Agradecimentos}

Aos meus pais e minha irmã pela educação e pelo o amor que sempre me deram;

Ao Tribunal de Contas da União, e em especial aos servidores da Secob-Rodovia, pelas contribuições com esta dissertação e pela oportunidade de participar do Mestrado Acadêmico na UnB;

Ao Secretário da Secob-Rodovia/TCU, Arsenio José da Costa Dantas, pelos ensinamentos imprescindíveis, pelos conselhos sempre oportunos, pela confiança e sobretudo pela sua sincera amizade;

À Universidade de Brasília pela oportunidade do conhecimento, juntamente com todo seu quadro docente e discente;

Ao professor Maurício Bugarin, pela confiança, orientação, suporte e comentários essenciais, sem os quais não seria possível concluir este trabalho;

À douta banca de mestrado pelas valiosas contribuições que aprimoraram esta dissertação;

Ao amigo e companheiro de Mestrado, Pedro Ghiraldini, pelas orientações e pelo auxílio no decorrer do curso de mestrado; 


\title{
Resumo
}

O trabalho testa a existência de viés no preço de contratação de obras públicas em favor de empresas que fazem doações às campanhas políticas. Para isso, utilizou-se um modelo econométrico estimado pelo método dos mínimos quadrados ordinários em seção cruzada. A amostra utilizada contém dados de 1107 contratos de obras rodoviárias no âmbito do Departamento Nacional de Infraestrutura de Transportes (DNIT) entre os anos de 2007 e 2013. Os resultados da estimação desse modelo indicaram que: licitações vencidas por empresas doadoras de campanha apresentaram desconto inferior às licitações vencidas pelas empresas não doadoras; no ano de 2011 o desconto nas licitações aumentou significativamente em relação ao ano de 2010, o que poderia ser explicado pela troca de comando do DNIT, decorrente de denúncias de corrupção nessa autarquia, ou ainda por influência do ciclo político; licitações de obras em regiões politicamente conectadas a gestores envolvidos em denúncias de corrupção apresentaram menores descontos.

Palavras chaves: Licitação, Obras Públicas, Doações de Campanha, Corrupção

\begin{abstract}
This work tests the existence of hiring price bias of public works in favor of companies that make donations to political campaigns. The econometric model was estimated by the method of ordinary least squares, cross-section, with 1107 contracts data under the National Department of Transport Infrastructure (DNIT) between the years 2007 and 2013. The estimation results of this model indicated that: bids won by corporate donors campaign had lower discount than bids won by non-corporate donors; DNIT's command exchange after corruption scandal in 2011 accounted for discount increase in bids in subsequent years; bids in regions politically connected to managers involved in allegations of corruption had lower discounts.
\end{abstract}

Key Words: Bidding, Public Work, Campaign Donations, Corruption 


\section{Sumário}

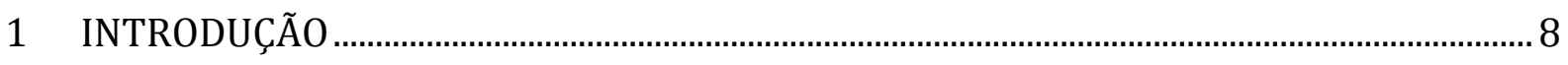

2 REVISÃO DA LITERATURA................................................................................................ 10

2.1 Doações de campanha como forma de consumo político ……………………………..... 10

2.2 Doações de campanha como forma de investimento......................................................... 11

2.4 Doações de campanha, compras públicas e obras públicas .............................................. 15

2.5 Formas de contratação de obras públicas ........................................................................ 19

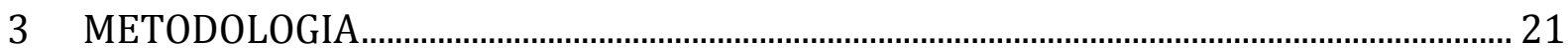

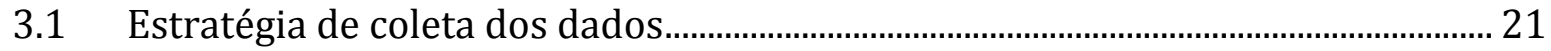

3.2 Análise e tratamento dos dados ............................................................................. 22

3.3 Modelo Econométrico................................................................................................... 22

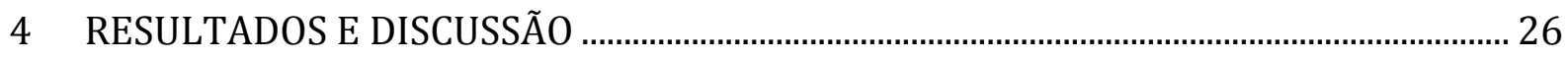

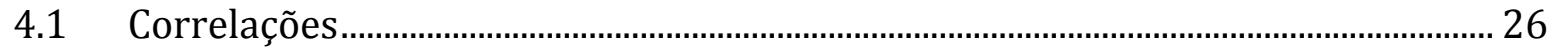

4.2 Resultados obtidos pelo Método de Estimação ……………………………………….... 28

4.2.1 Doações a campanhas eleitorais ...................................................................... 30

4.2.2 Região centro-oeste e denúncias de corrupção.................................................. 36

4.2.3 Denúncias de corrupção no Ministério dos Transportes e DNIT em 2011.37

4.2.4 Valores doados às campanhas ................................................................................. 39

4.2.5 Mudança da lei de licitações - Lei 8.666/1993 x Lei 12.462/2011 ................ 40

4.2.6 Local de licitação: sede do DNIT x superintendências regionais ...................... 40

4.2.7 Demais variáveis de controle ……………………………………………………..... 41

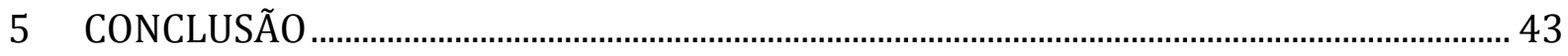

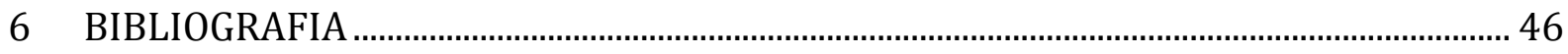

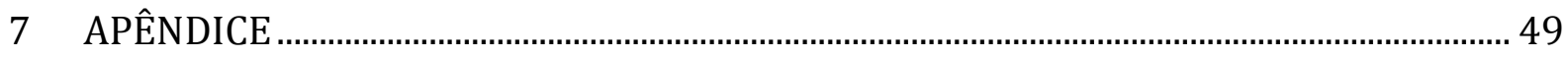




\section{Índice de Tabelas}

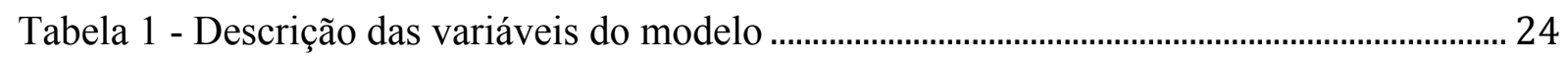

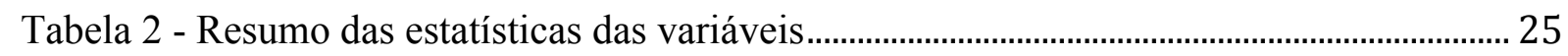

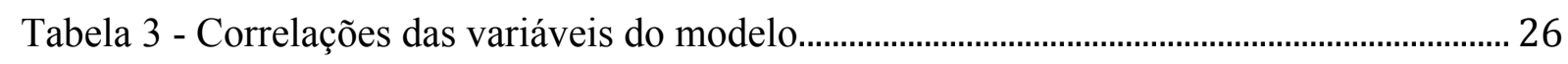

Tabela 4 - Resultados da estimação do modelo econométrico........................................................ 29

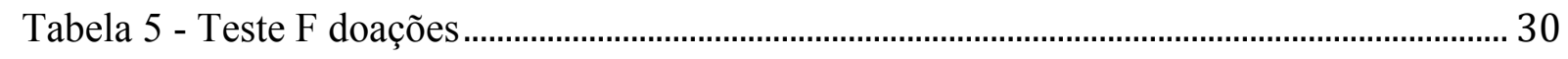

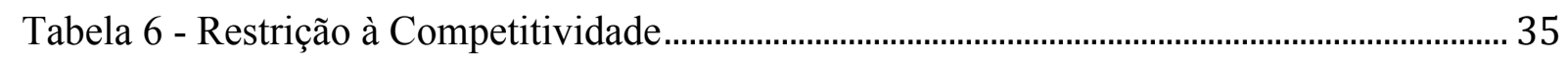

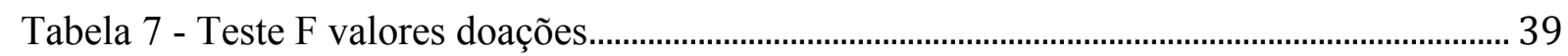

Tabela 8 - Pressuposto de normalidade dos resíduos da regressão.................................................. 49

Tabela 9 - Diagnóstico de homocedasticidade ................................................................................ 50 


\title{
1 INTRODUÇÃO
}

Existe atualmente, no Brasil e no exterior, grande preocupação com financiamento de campanhas eleitorais. Pode-se citar a recente votação no Supremo Tribunal Federal sobre a proibição de doações corporativas para as campanhas, expressa pelo voto de alguns de seus membros:

\begin{abstract}
No Brasil, os principais doadores de campanha contribuem para partidos com quem não têm identidade política e se voltam para obtenção de acordos com o governo. As empresas investem em todos os candidatos que têm chance de vitória. A comunidade jurídica nacional não pode acreditar num patrocínio desinteressado. A pretensão formulada dessa ação é indispensável para se colocar o fim da não equidade do processo eleitoral. Ministro Marco Aurélio ao votar contra doação eleitoral de empresas.

O financiamento fere profundamente o equilíbrio dos pleitos, que nas democracias deve se reger pelo princípio do "one man, one vote". A cada cidadão deve corresponder um voto, com igual peso e idêntico valor. As doações milionárias feitas por empresas a políticos claramente desfiguram esse princípio multissecular, pois as pessoas comuns não têm como contrapor-se ao poder econômico. Ministro Ricardo Lewandowski do STF ao votar contra doação eleitoral de empresas.
\end{abstract}

A preocupação está associada ao sentimento de que as empresas privadas que financiam as campanhas podem depois vir a influenciar o governo eleito por meio de conexões políticas, visto que o financiamento corporativo às campanhas no Brasil é preponderante: de acordo com dados do Tribunal Superior Eleitoral - TSE $^{1}$ para as eleições de 2010, 75\% das doações foram oriundas de pessoas jurídicas (empresas), 15\% de pessoas físicas e apenas $10 \%$ de recursos próprios dos candidatos.

Ainda de acordo com dados do $\mathrm{TSE}^{1}$, das 10 maiores contribuições de campanha nas eleições de 2012, 6 são oriundas de empresas do ramo da construção civil. Quando se compara as doações de empresas por segmentos econômicos, verifica-se que o setor de construção contribuiu com mais de 600 milhões de reais. O segundo segmento que mais contribuiu foi o da indústria de transformação, com valor pouco acima de 300 milhões.

A partir disso e considerando que, conforme Ministro Marco Aurélio, as empresas doam para com quem elas não têm identidade política, questiona-se: qual e como seria o retorno obtido pelas empresas da construção civil pelos vultosos investimentos realizados nas doações de campanha?

A literatura sobre o tema, no âmbito do Brasil, é praticamente inexistente. Alguns trabalhos apenas mencionam que as empresas doadoras obtém maior número de contratos com o poder público. Entretanto, considerando que a lei de licitações proíbe a adjudicação de

\footnotetext{
1 (http://www.tse.jus.br/eleicoes/estatisticas/estatisticas-eleicoes-2012)
} 
contratos sem licitação, como as empresas doadoras conseguiriam mais contratos públicos? E em quais condições?

Para tentar responder a essas questões, este trabalho testará a existência de viés na contratação de obras públicas de forma a beneficiar as empresas doadoras de campanha no âmbito das licitações de obras públicas rodoviárias a cargo do DNIT. O viés que se pretende estudar é variação de preço ou desconto ofertado nas licitações públicas em relação ao preço de referência da Administração (preço reserva).

Mais especificamente, o estudo testará se as licitações vencidas pelas empresas doadoras apresentam desconto menor que as licitações vencidas por empresas não doadoras. Para tanto, realizar-se-á regressão linear múltipla em 1107 contratos a cargo do Departamento Nacional de Infraestrutura de Transportes (DNIT) para os anos de 2007 a 2013. 


\section{REVISÃO DA LITERATURA}

A literatura sobre contribuições de campanha e conexões políticas apresenta várias vertentes de pesquisa acadêmica. Poderia haver muitas razões economicamente justificáveis para as empresas apoiarem algum candidato ou algum partido político. $\mathrm{Na}$ literatura existente prevalecem dois motivos: 1) contribuições de campanha como uma forma de consumo político (Ansolabehere, Figueiredo and Snyder, 2003). 2) contribuições de campanha como uma forma de investimento (Snyder, Jr., 1990).

\subsection{Doações de campanha como forma de consumo político}

Nos EUA, os autores Ansolabehere, Figueiredo e Snyder (2003) afirmam que a maior parte das contribuições de campanha nos Estados Unidos provém de doações individuais: $80 \%$; as empresas contribuem com 13\%; já o tesouro americano com $7 \%$. Considerando que grande parte da literatura e da crendice popular aceita que as contribuições de campanha são um investimento, os autores se perguntam por que existe tão pouco dinheiro corporativo na política dos Estados Unidos.

Os autores citam como exemplo as contribuições de \$10,6 milhões em 1998 oriundas das empresas ligadas ao setor de defesa do EUA frente ao orçamento de compra de material desse setor: $\$ 134$ bilhões ao ano. Por meio de testes econométricos os autores afirmam que as doações corporativas não conseguem influenciar significativamente as ações dos congressistas, visto que as contribuições individuais suplantam as doações corporativas.

Considerando essa baixa contribuição de campanha corporativa, Ansolabehere, Figueiredo e Snyder (2003) argumentam que os estudos que afirmam que as doações de campanha nos EUA são consideradas um investimento carecem de maiores aprofundamentos: qual seria a taxa de retorno sobre as contribuições? Qual seria o contribuinte marginal à política? Segundo os autores, os estudos que relacionam contribuições de campanha a investimentos tratam de compra de votos para aprovação de determinada legislação que beneficie os doadores. Informam que a maioria dos estudos não consegue encontrar relações consistentes entre doações de campanha e comportamento de voto de determinado congressista. Apenas um quarto dos estudos consegue alguma relação significativa.

Ansolabehere, Figueiredo e Snyder (2003) inferem que as pessoas fazem contribuições individuais porque são ideologicamente motivadas, porque elas estão animadas com a política, porque elas são convidadas pelos seus amigos ou colegas, e porque elas têm os recursos necessários para exercer essa forma particular de participação. Em suma, as pessoas 
fazem contribuições às campanhas por causa do valor do consumo associado com a política, e não porque elas recebem benefícios privados diretos. Os autores chamam esses doadores de "contribuintes de consumo". Eles representam a maior parte do dinheiro de campanha política dos Estados Unidos, e segundo os autores, impedem que as corporações consigam obter vantagens particulares por meio de contribuições de campanha.

Nesse sentido, no âmbito dos EUA, Aggarwal, Meschke e Wang (2012) não confirmaram a hipótese de que as doações de campanha representam um investimento em capital político. Em vez disso, afirmaram que doações políticas são sintomas de problemas de agência dentro das empresas.

\subsection{Doações de campanha como forma de investimento}

Snyder, Jr. (1990) afirma que grande parte dos estudiosos considera que doadores de campanha enxergam suas contribuições como um investimento, esperando algum retorno no futuro. Já os candidatos, esperam que as contribuições de campanha os ajudem a ganhar a eleição. A explicação é intuitiva: sobre as contribuições de campanha, assim como sobre todos os investimentos, são esperados uma de taxa de retorno, forçando os políticos a fornecerem aos doadores "benefícios" em troca de contribuições de campanha.

Snyder, Jr. (1990) criou modelo que explica o porquê das empresas realizarem esse investimento. O modelo consiste em um mercado no qual os agentes políticos estão competindo pelas doações de campanha. $\mathrm{O}$ autor infere em seu modelo que os candidatos maximizam suas contribuições por meio da venda de favores aos doadores corporativos. Ao longo do estudo discute que o valor das contribuições institucionais é função da probabilidade do candidato ganhar. Além disso, os candidatos que teriam maiores condições de vencer o pleito, receberiam maiores contribuições.

Esse modelo pode ser definido da seguinte forma: $P_{d} * G_{d j} \geq R_{d j} * X_{d j}$. As variáveis são assim definidas: $\mathrm{D}$ e $\mathrm{R}=$ candidatos; $\mathrm{J}=$ doador corporativo; $\mathrm{P}_{\mathrm{d}}=$ probabilidade do candidato $D$ ganhar as eleições; $G_{d j}=$ valor do favor vendido por $D$ a $J ; R_{d j}=$ taxa de retorno que $\mathrm{J}$ pode obter em um investimento "semelhante"; $X_{\mathrm{dj}}=$ quantia doada pelo doador $\mathrm{J}$ ao candidato D. O modelo considera ainda que o candidato D maximiza as contribuições que recebe para uma dada quantidade de promessa de favores, assim vale a igualdade: $\mathrm{P}_{\mathrm{d}} * \mathrm{G}_{\mathrm{dj}}=$ $\mathrm{R}_{\mathrm{dj}} * \mathrm{X}_{\mathrm{dj}}$

Simetricamente, para o candidato $R$, vale: $P_{r} * G_{r j}=\left(1-P_{d}\right) * G_{r j}=R_{r j} * X_{r j}$. Se os candidatos vendem a mesma quantidade de favor, em equilíbrio: 
$P_{d}=\frac{X d j}{X d j+X r j}=x d$

Se a quantidade de favor é diferente entre os candidatos, vale a seguinte relação:

$P_{d}=\frac{x d * G r j}{x d * G r j+(1-x d) * G d j}$

Se vale a última equação, então $G_{d j} \geq G_{r j}$, se e somente se, $P_{d}<\mathbf{x}_{\mathbf{d}}$. Isso é, se o candidato D promete maiores favores, ele receberá mais contribuições corporativas relativamente à sua probabilidade de ganhar do que o candidato $\mathrm{R}$.

Outro estudo nesse sentido é o de Samuels (2001) que argumenta que o sistema político do Brasil é organizado de modo a proporcionar compromissos críveis entre as empresas que fazem doações de campanha e os candidatos que retribuem esse investimento por meio de futuros favores. O autor afirma que a campanha política dos candidatos no Brasil é individualizada, por isso os políticos têm incentivos para desenvolver uma reputação de modo a cuidar dos interesses dos seus principais doadores de campanha durante o mandato. A maioria dos políticos brasileiros são políticos de carreira. Além disso, aqueles que deixam momentaneamente o Congresso Nacional, o fazem para continuar a carreira nos postos do poder executivo. Assim, a probabilidade de interações repetidas entre candidatos e doadores corporativos é alta.

Da mesma forma, Boas, Hidalgo e Richardson (2014), inferem que no caso do Brasil, o político que ajuda uma empresa a adquirir contratos com o governo, e não recebe nenhuma contribuição na próxima campanha, poderá reter futuros favores legislativos ou mesmo pressionar o executivo a suspender o desembolso de fundos previamente autorizados. Da mesma forma, as empresas que são rejeitadas pelos candidatos vitoriosos podem recusarse a contribuir na próxima campanha, ou mesmo financiar a oposição. Dado esse jogo repetido, as empresas e os políticos tendem a cultivar relacionamento de confiança e de reciprocidade no longo prazo, benéfico para ambos.

Por fim, Claessensa, Feijend e Laeven (2008) encontraram evidência empírica para a hipótese de que financiamento de campanha compra favores políticos para as empresas doadoras. Os autores exploraram uma série de dados ao nível empresa-candidato nas contribuições de campanha para as eleições de 1998 e 2002 no Brasil. Os autores constataram que o acesso ao financiamento bancário é um desses favores. 


\subsection{Doações de campanha e conexões políticas}

Claessensa, Feijend e Laeven (2008) consideraram que as contribuições realizadas às campanhas eleitorais no ambiente brasileiro consistem em conexões políticas. Segundo esses autores, o Brasil é conhecido pelas relações promíscuas entre políticos e empresas. Além disso, devido ao seu nível limitado de desenvolvimento institucional, o valor das ligações políticas no Brasil é provavelmente maior do que em países mais desenvolvidos. Grande parte desse valor poderia vir de um acesso preferencial ao financiamento, visto que o Brasil estava entre os países, na época avaliada pelo estudo (1998-2002) com as mais altas taxas de juros e o menor grau de intermediação financeira no mundo.

Além disso, segundo Claessensa, Feijend e Laeven (2008), os dois maiores bancos comerciais eram de propriedade do governo à época e uma grande parte do financiamento externo era controlada por bancos de desenvolvimento estatais, tornando o financiamento mais facilmente influenciado pelos políticos. Adicionalmente, o Brasil é um dos poucos países que registram as contribuições de campanha a nível candidato individual. A legislação brasileira determina registro individual e justificação de gastos de campanha por cada candidato.

Conforme Claessensa, Feijend e Laeven (2008), a lei torna mais difícil para um político gastar dinheiro não oficial em campanha. Embora ainda possa haver outras maneiras de influenciar políticos, contribuições de campanha são um importante meio para o fazer. Ademais, os autores afirmam que os dados de doações de campanha no Brasil oferecem três vantagens: (i) eles são mais objetivos em comparação com os dados normalmente utilizados nesta literatura para identificar se existe uma relação entre políticos e empresas; (ii) eles permitem medir a intensidade de uma conexão em vez de simplesmente indicar a sua presença.

A partir disso, os autores Claessensa, Feijend e Laeven (2008) confirmam a crescente literatura que diz que conexões políticas podem ter um impacto significativo sobre o valor da empresa e o acesso a financiamento bancário, no mesmo sentido dos trabalhos de (Johnson and Mitton, 2003), (Ferguson and Voth, 2008), (Khwaja and Mian, 2005), (Charumilind, Kali and Wiwattanakantang, 2006), (Cole, 2009), (Dinç, 2005).

Faccio (2006) em seu estudo coletou dados de 18.884 firmas que possuíam conexões políticas espalhadas em 42 países. A autora utilizou em seu estudo conexões políticas fortes, casos em que ministros de estado e membros do parlamento são sócios ou 
diretores das empresas que contratam com o governo. Além disso, a autora relatou a possibilidade de conexões políticas mais fracas como, por exemplo, empresas que contribuem para as campanhas de membros do parlamento ou ministros de estado.

Os resultados encontrados por Faccio (2006) indicam que empresas com conexões políticas: são mais comuns em países que possuem maior percepção de corrupção; lucram mais em países mais corruptos; têm fácil acesso a crédito bancário; pagam menos impostos; conseguem maior fatia de mercado; obtêm maiores benefícios quando as conexões políticas são mais fortes.

Faccio (2006) concluiu por meio de estudo de caso que as conexões políticas resultam em aumento significativo no valor das empresas que operam em países altamente corruptos. A autora afirma ainda que conexões políticas não agregam valor para as empresas que operam em países com baixos níveis de corrupção. Nesses países, por outro lado, a maioria das empresas decide não se envolver com conexões políticas. Por fim, a autora cita ainda que há uma relação positiva entre conexões políticas e corrupção, entretanto não foi possível identificar uma relação causal entre ambas.

O índice de percepção da corrupção ${ }^{2}$, uma escala que varia de 0-100 que indica que quanto maior o escore, mais limpo é o país e melhor colocado no ranking ele é, demonstra que em uma amostra de 177 países, o Brasil possui escore de 42, sendo o $72^{\circ}$ país mais limpo. Em outras palavras, o Brasil pode ser considerado um país relativamente corrupto, o que indica que, conforme estudo de Faccio (2006), pode haver uma forte relação entre conexão política e corrupção no Brasil.

Fisman (2001) em seu estudo comprova que as empresas que possuíam conexões políticas com o presidente Suharto da Indonésia experimentavam variações significativas no seu valor decorrente de fatos políticos relacionados com a vida desse presidente. Em contrapartida, empresas sem conexões políticas não sofriam variações significativas em seu valor de mercado. O autor sugere ainda que os resultados alcançados em seu estudo podem se aplicar a outros países com nível semelhante de corrupção medido pelo índice de percepção da corrupção. Conclui afirmando que esse índice de percepção da corrupção é uma importante proxy para se identificar se o valor das empresas estão sujeitas às conexões políticas. Cumpre mencionar que em 2013, o escore de percepção de corrupção da Indonésia é 32, ocupando a $114^{\mathrm{a}}$ posição.

\footnotetext{
${ }^{2}$ http://www.transparency.org/
} 
Faccio, Masulis e Mcconnell (2006) analisaram a possibilidade de ajuda do governo a 450 empresas com conexões políticas em 35 países no período de 1997 a 2002 . Os autores encontraram que as empresas com ligações políticas são significativamente mais propensas a serem socorridas que as empresas semelhantes sem conexões políticas. Além disso, as empresas com ligações políticas são desproporcionalmente mais propensas a serem socorridas quando o FMI ou o Banco Mundial prestam assistência financeira ao país de origem dessa empresa.

No caso do Brasil, o trabalho diário da mídia mostra que, em diversas esferas e instâncias, o poder público é permeável a pressões empresariais pontuais em defesa de benefícios particulares, por meio de corrupção, conexões políticas, dentre outras. Existe um amplo consenso em torno desse diagnóstico. (Mancuso, 2007)

Nem sempre empresas politicamente conectadas auferem vantagens. Fan, Wong e Zhang, (2007) destacam em seus estudos que aproximadamente 27\% dos CEOs em uma amostra de 790 empresas privatizadas parcialmente na China são antigos ou atuais burocratas do governo. As empresas com CEOs politicamente conectados possuem desempenho 18\% inferior àquelas empresas sem CEOs politicamente conectados, com base no retorno sobre suas ações três anos após o IPO. Além disso, após três anos após o IPO, essas empresas politicamente conectadas experimentaram menor crescimento dos lucros, menor crescimento das vendas, e menor retorno sobre vendas quando comparadas com empresas do mesmo ramo e não conectadas politicamente. Dessa forma, esse estudo mostra que nem sempre conexões políticas agregam valor à empresa.

Por fim, Svensson (2005) afirma que há uma variedade de evidências que sugerem que o aumento da concorrência, devido à desregulamentação e à simplificação de regras e leis, está negativamente correlacionada com a corrupção. Observa também que subornos tem um paralelo na forma de contribuições de campanha, mas eles não são substitutos perfeitos.

\subsection{Doações de campanha, compras públicas e obras públicas}

Segundo Boas, Hidalgo e Richardson (2014), a forma de retribuição dos políticos aos seus doadores de campanha corporativos depende do tipo de indústria envolvida. Firmas que estão sujeitas à supervisão do governo, como bancos privados, podem preferir uma regulação mais frouxa; as empresas que se baseiam pesadamente em crédito, como os 
produtores agrícolas, podem recorrer a empréstimos subsidiados do Banco Nacional de Desenvolvimento Social (BNDES).

Os autores Boas, Hidalgo e Richardson (2014) argumentam que a história de escândalos de financiamento de campanha no Brasil parece residir mais na indústria da construção civil, que possui substancial volume de recurso contratado com o governo federal. Esses contratos de obras públicas podem ser direcionados a empresas específicas.

Segundo Tollini (2009), os legisladores podem direcionar os gastos do governo federal por meio de uma variedade de mecanismos. O relatório anual do processo orçamentário começa com o executivo enviando um projeto de lei ao Congresso. Antes de ser agendada uma votação, o projeto é revisto e alterado pela Comissão do Orçamento. Dessa forma, o processo legislativo oferece aos legisladores múltiplas oportunidades para propor gastos que poderiam beneficiar seus doadores de campanha.

Não é incomum a proposta vencedora ter sido escolhida antes de o orçamento federal ter sido aprovado, conforme citam os autores Santos, Machado e Rocha (1997). Além disso, conforme Krieger, Rodrigues e Bonassa (1994), a empresa em questão pode até elaborar a emenda que autoriza a despesa.

Boas, Hidalgo e Richardson (2014) argumentam que uma vez que o orçamento já foi transformado em lei e entra em vigor, o jogo entra em uma fase focada no poder executivo. Apesar da aparente falta de poder de decisão nesta etapa, os legisladores desempenham um papel fundamental no lobby junto ao executivo para conseguir que as verbas orçamentárias sejam gastas por meio da contratação de sua empreiteira doadora de campanha. Os autores argumentam que apesar da contratação ser posterior à confecção da lei do orçamento, muitas vezes há pouca dúvida a respeito de quem será contratado para levar a cabo um determinado projeto.

Segundo relatado no livro dos autores Krieger, Rodrigues e Bonassa (1994), tradicionalmente, os doadores de campanha e os políticos têm tomado suas obrigações recíprocas muito a sério, por meio de criação de acordos cuidadosamente especificados, envolvendo contratos com o governo, propinas e doações de campanha. Em um escândalo político descoberto em 1993 (Anões do Orçamento), membros da comissão de orçamento do congresso brasileiro foram denunciados por aceitarem pagamentos de um cartel de empresas de construção civil para obtenção de vantagens em contratos de obras públicas inseridas no orçamento federal. Documentos internos do líder do cartel especificaram uma tabela de preços 
para as obras inseridas no orçamento da União. Incialmente, os políticos recebiam propinas em dinheiro vivo, em torno de 3\% sobre cada projeto aprovado. Entretanto, quando doações de campanha das empresas foram legalizadas em 1993, a compensação das empresas pelos favores políticos continuaram por esse caminho menos arriscado (contribuições de campanha). Dessa forma, pode-se dizer que a conexão política entre empreiteiras e políticos se dá por meio das contribuições de campanha.

Conforme noticiado pela imprensa brasileira $^{3}$, o delator do escândalo conhecido como Petrolão, Sr. Alberto Youssef, em depoimentos à Polícia Federal e ao Ministério Público, relatou que as "doações legais" das empreiteiras às campanhas políticas foram a fórmula criada para esconder a propina aos políticos envolvidos no esquema de corrupção da Petrobrás. Assim, pode-se dizer que a conexão política entre empreiteiras e políticos se dá por meio das contribuições de campanha.

Em 2011, o deputado aliado ao governo federal que dirigiu o Ministério dos Transportes foi acusado de ter usado sua influência no DNIT para solicitar propina de empresas de construção de obras rodoviárias. As firmas seriam obrigadas a pagar $4-5 \%$ do valor dos contratos ${ }^{4}$.

Rumba e Jasčišens (2009) mostram que as empresas com ligações políticas decorrentes de doações a partidos políticos obtêm benefícios em contratos públicos na Letônia. O principal benefício obtido por essas empresas é participar de licitações públicas em um ambiente com $20 \%$ menos concorrência em relação às empresas que não possuem ligações políticas. Em outras palavras, as licitações nas quais as empresas com ligações políticas lograram vencer ocorreram em um ambiente com $20 \%$ menos concorrência do que nas licitações vencidas por empresas sem ligações políticas.

Além disso, Rumba e Jasčišens (2009) mostram que a possível fonte da diminuição da concorrência deve-se às especificações técnicas tendenciosas. Os resultados dos autores também revelaram que as empresas com ligações políticas são mais propensas a participarem de processos de adjudicação de contratos públicos menos transparentes. Os autores concluem que não se pode rejeitar que os contratos públicos são uma fonte de maior desempenho para as empresas politicamente conectadas.

\footnotetext{
3 http://veja.abril.com.br/noticia/brasil/youssef-doacao-era-propina

${ }^{4}$ http://www1.folha.uol.com.br/poder/2011/07/945936-veja-a-cronologia-da-crise-no-ministerio-dostransportes.shtml
} 
Por fim, Rumba e Jasčišens (2009) finalizam afirmando que o ambiente de menor concorrência proporcionado pelas ligações políticas tem implicações enormes para a economia como um todo, pois dificulta a concorrência no mercado, cria perdas de eficiência e incentiva o investimento ineficaz, decorrente de conexões políticas existentes.

Coviello e Gagliarducci (2010) utilizaram um conjunto de dados de licitações sob responsabilidade de diversos prefeitos de cidades italianas para fornecer evidência empírica referente ao poder de influência desses políticos nas contratações públicas. O principal resultado obtido é que, quando os políticos se mantêm no poder por um longo período de tempo, há uma deterioração sistemática do funcionamento do mecanismo de licitação: observou-se uma menor concorrência, um maior custo de obras públicas, e um aumento na probabilidade do vencedor ser uma empresa com ligações políticas e uma maior probabilidade de uma empresa sair vencedora mais frequentemente.

No tocante às obras públicas, Coviello e Gagliarducci (2010) ressaltam que as obras licitadas no segundo mandato de um prefeito apresentam descontos na licitação 5,7\% inferior às obras públicas licitadas no primeiro mandato. Além disso, a concorrência dos certames é reduzida em $11,7 \%$, ou seja, o número de concorrentes diminui.

Os autores Coviello e Gagliarducci (2010) constataram, de acordo com dados expost sobre execuções de obras, e sobre compras de bens e serviços padronizados, que seus achados provam que quando um prefeito permanece no poder por um período mais longo, há uma maior probabilidade de conluio. Inferem ainda que explicações alternativas, como inexperiência dos prefeitos e suposta diferença de qualidade entre os licitantes não encontram respaldo em seus estudos. Por fim, os autores concluem que um regulador interessado na racionalização dos gastos públicos deve incentivar a implementação de políticas que favoreçam a rotatividade política, de tal forma que a concorrência nas licitações possa ser restaurada.

Goldman, Rocholl e So (2008) avaliaram em seu estudo se as conexões políticas nos Estados Unidos afetaram a alocação de contratos adjudicados para empresas com essas conexões após a eleição de meio termo de 1994, ano em que o controle majoritário da Câmara e do Senado muda do Partido Democrata para o Partido Republicano e após a eleição presidencial de 2000 na qual a Presidência muda do Partido Democrata para o Partido Republicano. 
As principais conclusões de Goldman, Rocholl e So (2008) são que, após essas eleições, empresas ligadas aos republicanos são mais propensas a experimentar um aumento no valor total de seus contratos, enquanto as empresas democratas são mais propensas a experimentar uma respectiva redução. Esses resultados permanecem estatisticamente significativos após o controle de características da empresa, geografia, bem como a indústria em que a empresa opera. Os resultados sugerem que, mesmo dentro do forte sistema legal dos EUA, conexões políticas têm um impacto significativo sobre a alocação de recursos do governo.

Boas, Hidalgo e Richardson (2014) afirmam que a vitória eleitoral de um candidato no Brasil traz aumentos substanciais no número de contratos com o governo para seu doador de campanha.

De acordo com Mironov e Zhuravskaya (2012) firmas russas que têm pelo menos $5 \%$ de suas receitas provenientes de contratos públicos fazem transferências anormalmente elevadas perto da data da eleição em relação às empresas que não possuem receitas provenientes de contratos públicos. Em particular, o autor observou um aumento substancial das doações iniciando três semanas antes da eleição, persistindo até quatro semanas após a eleição.

$\underline{2.5 \text { Formas de contratação de obras públicas }}$

Há significativa literatura dedicada à análise de contratos ideais para licitação. De acordo com o modelo formal derivado por McAfee e McMillan, (1986) é eficiente o governo utilizar licitações do tipo "contratos de incentivo" no qual o pagamento depende tanto do valor do lance ofertado pelo vencedor da licitação como também pela realização dos custos incorridos na execução do contrato. Se a realização do custo da empresa superar o valor do seu lance na licitação, a Administração absorve parte desses custos extras; caso contrário, a Administração também lucra com parte da realização do custo abaixo do lance dado pela empresa na licitação.

No entanto, McAfee e McMillan (1986) observam que a maior parte das licitações nos EUA não segue o modelo de contratos de incentivo, mas sim o modelo de contratos de preço fixo, no qual, independentemente de qualquer coisa, a empresa receberá pela execução do contrato o valor do preço que ela ofertou na licitação. O autor cita ainda o modelo de contrato de custo adicional, no qual a Administração é responsável por todo o aumento de 
custo incorrido pelo executor do contrato, conclui que essa forma de contrato só é eficiente quando há apenas um licitante.

Bower (1993) concluiu em seu estudo que de fato os "contratos de incentivo" apresentam ganhos consideravelmente superiores para o governo nas licitações públicas quando comparados com os demais tipos de contrato citados no parágrafo anterior. Entretanto, o autor observou também que o aumento do número de licitantes tende a anular as ineficiências das outras formas de contratação, de forma a convergir os ganhos do governo para um valor comum, partindo de qualquer uma das três formas de contratação.

Porter e Zona (1993) estudaram metodologia para identificar conluios entre os licitantes de obras públicas rodoviárias no Estado de Nova Iorque. Concluíram que não se pode rejeitar a hipótese de existência de propostas fantasmas realizadas por algumas empresas, de forma apenas a ludibriar o poder público, de forma a passar uma imagem de falsa concorrência. A partir dessa análise, concluem que a ordenação dos custos das empresas não coincide com a ordenação dos lances ofertados pelas empresas nas licitações.

Os autores Porter e Zona (1993) afirmaram ainda que no caso de cartéis não inclusivos, os lances ofertados pelo cartel e pelas empresas competitivas serão consistentes com as assimetrias de custos entre esses participantes. Isso posto, há a possibilidade do cartel não inclusivo lucrar nos casos em que seus custos são inferiores aos custos das empresas competitivas.

Por fim, os autores Porter e Zona (1993) citam que é extremamente difícil identificar a presença de cartéis. Cita como exemplo a sua própria metodologia de identificação: caso fosse divulgada pelos fiscais públicos do Governo dos EUA, haveria possibilidade dos licitantes ludibriarem a fiscalização para falsear o diagnóstico proposto por sua metodologia. 


\section{METODOLOGIA}

A pesquisa documental para realização deste trabalho foi realizada: na base de dados de licitações do Departamento Nacional de Infraestrutura em Transportes, publicado no sítio eletrônico da autarquia na internet; na base de dados de licitações realizadas na forma eletrônica, por meio do sítio eletrônico Comprasnet, mantido pelo Governo Federal; na prestação de contas das eleições de 2010 e 2012, publicadas no sítio eletrônico do Tribunal Superior Eleitoral (TSE) e no Sistema de Cadastramento Unificado de Fornecedores (SICAF).

\subsection{Estratégia de coleta dos dados}

Os dados coletados dos sistemas informatizados foram reunidos em uma planilha eletrônica, para posterior inserção no software Stata 11. Inicialmente, coletaram-se os dados relativos às licitações no sítio eletrônico do DNIT ${ }^{5}$.

Posteriormente, adicionaram-se os dados das licitações realizadas eletronicamente por meio do sistema Comprasnet, do Governo Federal ${ }^{6}$. Em seguida, coletaram-se dados do sistema Sindec, mantido pelo $\mathrm{DNIT}^{7}$ como forma de se obter informações sobre os contratos. Dessa forma, formou-se a base de dados primária com 1107 obras referentes aos anos de 2007 a 2013, perfazendo valor superior a 47 bilhões de reais.

Cumpre mencionar que as licitações anteriores a 2007 não constam dos sistemas eletrônicos da autarquia. Para sistematizar as informações dessas obras seria necessário acesso aos processos físicos, em papel, espalhados pelas Superintendências Regionais do DNIT nos 26 estados brasileiros, o que não foi possível realizar no presente trabalho.

Os dados sobre o tamanho das empresas licitantes foram coletados do Sistema de Cadastramento Unificado de Fornecedores $\operatorname{SICAF}^{8}$ do governo Federal, tendo como referência as situações das empresas no ano de 2013.

A partir da base primária dos 1107 empreendimentos, adicionaram-se dados referentes às doações a campanhas eleitorais, separadas em três grupos, coletados das prestações de contas à justiça eleitoral ${ }^{9}$.

O primeiro grupo refere-se ao valor das doações das empresas contratadas pelo DNIT ao partido e ao candidato vencedor da eleição presidencial do ano de 2010. Para obter

\footnotetext{
${ }^{5} \mathrm{http}: / /$ www.dnit.gov.br/licitacoes

$6 \mathrm{http} / / /$ compras.dados.gov.br/

7 http://dwsindec.dnit.gov.br/asp/main.aspx

${ }^{8} \mathrm{https://www3.comprasnet.gov.br/SICAFWeb/index.jsf}$

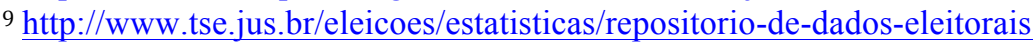


esse valor, somaram-se as doações dessas empresas ao candidato, ao partido e ao comitê de campanha, obtendo assim o total doado por empresa às eleições presidenciais do candidato vencedor.

O segundo grupo traz à baila o valor das doações das empresas contratadas pelo DNIT aos candidatos a governador, deputados federais e senadores no ano de 2010. Esse valor foi obtido pela soma dos valores doados pelas empresas vencedoras ao candidato, ao partido e ao comitê de campanha dos partidos, sem distinção entre candidatos eleitos ou não eleitos, em função da grande diversidade de coligações nos estados da federação, própria do sistema presidencialismo de coalizão.

O terceiro e último grupo diz respeito ao valor das doações das empresas contratadas pelo DNIT aos candidatos aos cargos de prefeito e vereador no ano de 2012. Esse valor foi obtido pela soma dos valores doados pelas empresas vencedoras diretamente aos candidatos a prefeito (vereadores foram excluídos), ao partido e ao comitê de campanha dos partidos, sem distinção entre candidatos eleitos ou não eleitos.

3.2 Análise e tratamento dos dados

Para atingir os objetivos - verificar a existência de viés na contratação de obras públicas rodoviárias no âmbito do Departamento Nacional de Infraestrutura em Transportes (DNIT), por meio do desconto obtido nas licitações - foi escolhida uma abordagem metodológica de natureza quantitativa.

Para quantificar a influência das variáveis preditoras dessa variação de preço, ou seja, a variação do desconto obtido pela Administração na licitação de obras públicas, realizaram-se análises multivariadas, utilizando o software Stata, versão 11, com destaque para as análises de correlação e de regressão linear múltipla. Outros trabalhos também utilizaram estas análises, a exemplo de (Resnick e Zeckhauser, 2002), (Brülhart e Trionfetti, 2004), (Daly e Nath, 2005), (Lösch, 2006), (Engelbrecht-Wiggans e Katok, 2007) e (Teo, Lin e Lai, 2009).

\subsection{Modelo Econométrico}

No propósito de se verificar a existência de viés na contratação de obras públicas rodoviárias no âmbito do Departamento Nacional de Infraestrutura em Transportes (DNIT), por meio do desconto obtido nas licitações, testaram-se as variáveis descritas na Tabela 1 - 
Descrição das variáveis do modelo. A partir dessas variáveis, propôs-se estudar três modelos estatísticos, sendo desconto a variável dependente:

(1) desconto $=\mathbf{B}_{0}+\mathbf{B}_{1-3} *($ doações $)+\mathbf{B}_{4-7} *($ regiões $)+B_{8-13} *($ anos $)+B_{17-28} *($ controle $)+u$

(2) desconto $=\mathbf{B}_{0}+\mathbf{B}_{4-7} *($ regiões $)+\mathbf{B}_{8-13} *($ anos $)+B_{14-16} *($ valores doações $)+B_{17-28} *($ controle $)+u$

(3) desconto $=\mathbf{B}_{0}+\mathbf{B}_{1-3} *($ doações $)+\mathbf{B}_{4-7} *($ regiões $)+\mathbf{B}_{8-13} *($ anos $)+\mathbf{B}_{14-16} *($ valores doações $)+\mathbf{B}_{17-28} *($ controle $)+\mathbf{u}$

$\mathbf{B}_{0}$ se refere à constante do modelo; $\mathbf{B}_{1-3}$ refere-se aos coeficientes das variáveis dummys relacionadas às doações de campanha (doações). $\mathbf{B}_{4-7}$ refere-se aos coeficientes das variáveis dummys relacionadas às regiões geográficas do Brasil (regiões). De forma similar, os vetores $\mathbf{B}_{\text {8-13, }} \mathbf{B}_{14-16}$, e $\mathbf{B}_{17-28}$ referem-se aos coeficientes das variáveis anos, valores de doações, e controle, respectivamente. Essas variáveis estão detalhadas na Tabela 1 - Descrição das variáveis do modelo. 
Tabela 1 - Descrição das variáveis do modelo

\begin{tabular}{|c|c|c|}
\hline & Descrição & inal \\
\hline Desconto & $\begin{array}{l}\text { variável a ser explicada pelo modelo. Ela corresponde } \\
\text { à variação percentual que a licitação proporcionou ao } \\
\text { preço de venda do produto. o seu cálculo se dá pela } \\
\text { diferença entre o preço ofertado pela empresa } \\
\text { vencedora (pv) e o preço reserva da Administração (pr) } \\
\text { sobre o (pr), conforme equaça a seguir: Yn = (pr - } \\
\text { pv)/(pr) Esta variável reflete o ganho ou perda que o } \\
\text { órgão público obteve ao comprar por meio de licitação. } \\
\text { valores multiplicados por } 100\end{array}$ & Sem interpretação do sinal. \\
\hline & $\begin{array}{l}\text { Variável Dummy que identifica com } 1 \text { se a empresa } \\
\text { vencedora da licitação realizou doação a candidatos ou } \\
\text { partidos políticos no ano de } 2010 \text { - Governadores, } \\
\text { Deputados e senadores }\end{array}$ & $\begin{array}{l}\text { Sinal negativo, pois espera-se que } \\
\text { empresas que doam a campanhas } \\
\text { eleitorais poderão vencer licitaçoses } \\
\text { ofertando menores descontos }\end{array}$ \\
\hline & 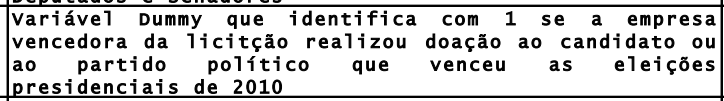 & $\begin{array}{l}\text { Sinal negativo, pois espera-se que } \\
\text { empresas que doam a campanhas } \\
\text { eleitorais poderäo vencer licitaçós } \\
\text { ofertando menores descontos }\end{array}$ \\
\hline & $\begin{array}{l}\text { Variável Dummy que identifica com } 1 \text { se a e } \\
\text { vencedora da licitção realizou doação a candida } \\
\text { partidos políticos no ano de } 2012 \text { - candic } \\
\text { prefeito, comitês e partidos elejtorais }\end{array}$ & $\begin{array}{l}\text { Sinal negativo, pois espera-se que } \\
\text { empresas que doam a campanhas } \\
\text { eleitorais poderão vencer licitaços } \\
\text { ofertando menores descontos }\end{array}$ \\
\hline$g$ & $\begin{array}{l}\text { Variável Dummy que atribui l para a obra realizada em } \\
\text { determinada região e o para as demais. Convencionou-se } \\
\text { ocultar a dummy referente à região norte. Cumpre } \\
\text { destacar que a região centro oeste é o local dos } \\
\text { principais envolvidos no escândalo de corrupção no } \\
\text { Dnit no ano de } 2011\end{array}$ & $\begin{array}{l}\text { Sinal negativo para a região centro } \\
\text { oeste devido aos escândalos de } \\
\text { corrupção no Dnit e no Ministério dos } \\
\text { Transportes envolvendo essa região }\end{array}$ \\
\hline hos das & $\begin{array}{l}\text { Variáve } 1 \text { Dummy que atribui } 1 \text { para o ano em que a obra } \\
\text { foi licitada e o para os demais. A amostra de 1107 } \\
\text { obras é distribuída entre os anos de } 2007 \text { e 2013. A } \\
\text { variáve } 1 \text { oculta é o ano de } 2011 \text {, quando ocorreu o } \\
\text { escândalo no ministério dos Transportes e no Dnit }\end{array}$ & $\begin{array}{l}\text { sinal positivo para o ano de 2011, } \\
\text { referentes aos ano que ocorreu o } \\
\text { escândalo no Ministério dos } \\
\text { Trasnportes e no Dnit com consequente } \\
\text { troca de comando da autarquia }\end{array}$ \\
\hline & $\begin{array}{l}\text { Variável que especifica a soma dos valores doados pela } \\
\text { empresa vencedora da licitação a candidatos ou } \\
\text { partidos políticos no ano de } 2010 \text { - Governadores, } \\
\text { Deputados e senadores - valores em milhöes de reais }\end{array}$ & $\begin{array}{l}\text { Sinal negativo, pois quanto maior o } \\
\text { valor doados pelas empresas, menores } \\
\text { serão os descontos necessários para } \\
\text { elas vencerem as licitaçoses }\end{array}$ \\
\hline$s$ & $\begin{array}{l}\text { el que especifica o valor doado pela empresa } \\
\text { ora da licitação ao candidato ou partido } \\
\text { co que venceu as eleições presidenciais de } 2010 \\
\text { s em milhóes de reais }\end{array}$ & $\begin{array}{l}\text { Sinal negativo, pois } \\
\text { valor doados pelas emp } \\
\text { serão os descontos ne } \\
\text { elas vencerem as licita }\end{array}$ \\
\hline & $\begin{array}{l}\text { Variável que especifica o valor doado pela empresa } \\
\text { vencedora da licitação a candidatos ou partidos } \\
\text { políticos no ano de } 2012 \text { em nível sub-Nacional - } \\
\text { candidato a prefeito, comitês e partidos eleitorais - } \\
\text { valores em milhóes de reais }\end{array}$ & $\begin{array}{l}\text { Sinal negativo, pois quanto maior o } \\
\text { valor doados pelas empresas, menores } \\
\text { serão os descontos necessários para } \\
\text { elas vencerem as licitacóes }\end{array}$ \\
\hline & 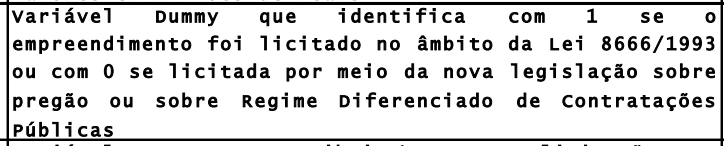 & $\begin{array}{l}\text { Sinal negativo, pois espera-se que a } \\
\text { nova legislação sobre licitações tenha } \\
\text { evoluído o modelo praticado sob a } \\
\text { égide da Lei } 8666 / 1993 \text {, ou seja, sob a } \\
\text { nova legislação a Administração } \\
\text { consiga maiores descontos }\end{array}$ \\
\hline & $\begin{array}{l}\text { Variável Dummy que atribui } 1 \text { para a licitação que } \\
\text { ocorreu na sede do DNIT em Brasília ou o para as } \\
\text { licitações ocorridas nas superintendencias da } \\
\text { autarquia nos estados }\end{array}$ & $\begin{array}{l}\text { Sinal positivo, pois as licitações } \\
\text { ocorridas em Brasilia tendem a ser } \\
\text { mais imparciais do que aquelas } \\
\text { ocorridas nos estados, onde os } \\
\text { gestores estão mais sujeitos à } \\
\text { ingerências dos licitantes }\end{array}$ \\
\hline antes & $\begin{array}{l}\text { variável que especifica o número de empresas que foram } \\
\text { habilitadas e participaram da licitação - variável } \\
\text { licitantes. Foi incluída também sua forma quadrática } \\
\text { para poder captar possível efeito negativo - } \\
\text { Qlicitantes. }\end{array}$ & $\begin{array}{l}\text { Sinal positivo para a variável } \\
\text { "licitantes", pois quanto maior a } \\
\text { concorrência, maior a disputa e o } \\
\text { desconto ofertado na licitaço e sinal } \\
\text { negativo para variável "Qlicitantes" } \\
\text { que capta efeito quadrático negativo }\end{array}$ \\
\hline & $\begin{array}{l}\text { As obras foram divididas em três grupos, por meio de } \\
\text { variável dummy, começando pelas obras mais complexas. } \\
\text { o primeiro grupo representa as obras de implantação, } \\
\text { duplicação e restauração; o segundo grupo as obras de } \\
\text { crema (manutenção); e o terceiro grupo as obras de } \\
\text { conservação. optou-se por ocultar a dummy referente ao } \\
\text { grupo 1, obras mais complexas }\end{array}$ & $\begin{array}{l}\text { Sinal positivo para os os grupos } 2 \text { e } \\
\text { 3. Quanto menos complexa a obra, menor } \\
\text { é o risco do contratado, aumentando } \\
\text { assim o desconto ofertado na licitação } \\
\text { em relação às obras de construção } \\
\text { Rodoviária, que são mais complexas }\end{array}$ \\
\hline tes & $\begin{array}{l}\text { Dummy que atribui o valor } 1 \text { para as } \\
\text { ações que possuem mais de um lote no mesmo } \\
\text { l, em outras palavras, licitação de vários } \\
\text { atos em um mesmo edital }\end{array}$ & $\begin{array}{l}\text { Sinal negativo, pois quanto mais lotes } \\
\text { licitados, maior a oferta, } \\
\text { consequentemente menores os descontos } \\
\text { ofertados na licitaça }\end{array}$ \\
\hline & $\begin{array}{l}\text { variáve } 1 \text { que especifica o número de contratos que a } \\
\text { empresa vencedora já possuiu ou possui com o DNIT } \\
\text { entre os anos de } 2007 \text { e } 2013\end{array}$ & $\begin{array}{l}\text { Sinal positivo, pois fornecedores que } \\
\text { prezam relacionamentos mais duradouros } \\
\text { fazem maiores esforços para continuar } \\
\text { o fornecimento e para isso são } \\
\text { obrigados a reduzir seus precos. }\end{array}$ \\
\hline & $\begin{array}{l}\text { Variável que especifica o percentual de aditivo em } \\
\text { relação ao valor inicial do contrato obtido pelas } \\
\text { empresas ao longo de sua execucaa }\end{array}$ & $\begin{array}{l}\text { Sinal negativo, pois quanto maior o } \\
\text { aditivo, maior risco à execução do } \\
\text { contrato e menor o desconto ofertado } \\
\text { pela empresa por ocasião da licitação }\end{array}$ \\
\hline & Variável que especifica o valor do Edital - Valores em & $\begin{array}{l}\text { Sinal negativo, pois quanto mai } \\
\text { valor do Edital, menos empresas } \\
\text { habilitadas a participar da licita } \\
\text { diminuindo a concorrência e o desc } \\
\text { ofertado na licitaçäo }\end{array}$ \\
\hline talAtivo & $\begin{array}{l}\text { Variável que especifica o total de ativos das empresas } \\
\text { licitantes em relação ao ano de } 2013 \text {. Valores em } \\
\text { milhões de reais }\end{array}$ & $\begin{array}{l}\text { Sinal positivo, pois esta variável é } \\
\text { uma proxy para custo, e empresas com } \\
\text { menores custos conseguem ofertar } \\
\text { maiores descontos nas licitações em um } \\
\text { ambiente competitivo }\end{array}$ \\
\hline
\end{tabular}

Fonte: elaboração do autor 
A Tabela 2 - Resumo das estatísticas das variáveis, retrata as principais estatísticas dessas variáveis, como média, desvio padrão, mínimos e máximos.

Tabela 2 - Resumo das estatísticas das variáveis

\begin{tabular}{|c|c|c|c|c|c|}
\hline Variable & Obs & Mean & std. Dev. & Min & Max \\
\hline $\begin{array}{r}\text { desconto } \\
\text { doacao2010 } \\
\text { doacaopres } \\
\text { doacao2012 } \\
\text { regiaon }\end{array}$ & $\begin{array}{l}1107 \\
1107 \\
1107 \\
1107 \\
1107\end{array}$ & $\begin{array}{l}16.25715 \\
.6251129 \\
.1246612 \\
.3279133 \\
.1490515\end{array}$ & $\begin{array}{l}15.65046 \\
.4843125 \\
.3304837 \\
.4696652 \\
.3563002\end{array}$ & $\begin{array}{r}-1.055916 \\
0 \\
0 \\
0 \\
0\end{array}$ & $\begin{array}{r}58.7589 \\
1 \\
1 \\
1 \\
1\end{array}$ \\
\hline $\begin{array}{r}\text { regiaose } \\
\text { regiaone } \\
\text { regiaos } \\
\text { regiaoco } \\
\text { ano2007 }\end{array}$ & $\begin{array}{l}1107 \\
1107 \\
1107 \\
1107 \\
1107\end{array}$ & $\begin{array}{r}.2448058 \\
.2484192 \\
.1915086 \\
.166215 \\
.0162602\end{array}$ & $\begin{array}{l}.4301663 \\
.4322914 \\
.3936662 \\
.3724418 \\
.1265315\end{array}$ & $\begin{array}{l}0 \\
0 \\
0 \\
0 \\
0\end{array}$ & $\begin{array}{l}1 \\
1 \\
1 \\
1 \\
1\end{array}$ \\
\hline $\begin{array}{l}\text { ano2 } 2008 \\
\text { ano2 } 009 \\
\text { ano2010 } \\
\text { ano2011 } \\
\text { ano2012 }\end{array}$ & $\begin{array}{l}1107 \\
1107 \\
1107 \\
1107 \\
1107\end{array}$ & $\begin{array}{l}.1915086 \\
.1815718 \\
.1056911 \\
.1237579 \\
.2782294\end{array}$ & $\begin{array}{r}.3936662 \\
.3856655 \\
.3075808 \\
.329454 \\
.4483296\end{array}$ & $\begin{array}{l}0 \\
0 \\
0 \\
0 \\
0\end{array}$ & $\begin{array}{l}1 \\
1 \\
1 \\
1 \\
1\end{array}$ \\
\hline $\begin{array}{r}\text { ano2013 } \\
\text { v1 rdoac2010 } \\
\text { v1 rdoacpres } \\
\text { v1 rdoac2012 } \\
\text { 1e } 18666\end{array}$ & $\begin{array}{l}1107 \\
1107 \\
1107 \\
1107 \\
1107\end{array}$ & $\begin{array}{r}.102981 \\
1.198704 \\
.1622729 \\
.5643271 \\
.7244806\end{array}$ & $\begin{array}{r}.3040715 \\
4.63398 \\
.7721873 \\
4.031674 \\
.4469776\end{array}$ & $\begin{array}{l}0 \\
0 \\
0 \\
0 \\
0\end{array}$ & $\begin{array}{r}1 \\
83.21712 \\
13 \\
52.135 \\
1\end{array}$ \\
\hline $\begin{array}{r}\text { 1icitadosede } \\
\text { 1jcitantes } \\
\text { q1icitantes } \\
\text { grupo1 } \\
\text { grupo2 }\end{array}$ & $\begin{array}{l}1107 \\
1107 \\
1107 \\
1107 \\
1107\end{array}$ & $\begin{array}{r}.298103 \\
7.472448 \\
82.68473 \\
.2863595 \\
.3893406\end{array}$ & $\begin{array}{l}.4576317 \\
5.183775 \\
120.6739 \\
.4522638 \\
.4878211\end{array}$ & $\begin{array}{l}0 \\
1 \\
1 \\
0 \\
0\end{array}$ & $\begin{array}{r}1 \\
34 \\
1156 \\
1 \\
1\end{array}$ \\
\hline $\begin{array}{r}\text { grupos } \\
\text { lotes } \\
\text { numcontratos } \\
\text { aditivos } \\
\text { v1redital }\end{array}$ & $\begin{array}{l}1107 \\
1107 \\
1107 \\
1107 \\
1107\end{array}$ & $\begin{array}{l}.3242999 \\
.2601626 \\
20.63866 \\
11.41021 \\
41.66782\end{array}$ & $\begin{array}{l}.4683243 \\
.4389215 \\
29.78855 \\
25.84712 \\
65.59494\end{array}$ & $\begin{array}{r}0 \\
0 \\
1 \\
-35.03 \\
.1490619\end{array}$ & $\begin{array}{r}1 \\
1 \\
100 \\
369.21 \\
605.4526\end{array}$ \\
\hline totalativo & 1107 & 538.1962 & 9011.423 & 0 & 299686.2 \\
\hline
\end{tabular}

Fonte: elaboração do autor 


\section{RESULTADOS E DISCUSSÃO}

\subsection{Correlações}

Para verificar a existência de relação linear entre as variáveis utilizadas e o desconto obtido nas licitações, primeiramente realizou-se teste de correlação simples de Pearson. Além disso, listaram-se as correlações entre as variáveis independentes e os dados sobre doações de campanha, conforme Tabela 3 - Correlações das variáveis do modelo

Tabela 3 - Correlações das variáveis do modelo

\begin{tabular}{|c|c|c|c|c|c|c|c|}
\hline Variáveis & Desconto & $\begin{array}{c}\text { Doação } \\
2010\end{array}$ & $\begin{array}{c}\text { Doação } \\
\text { Presiden } \\
\text { cial }\end{array}$ & $\begin{array}{c}\text { Doação } \\
2012\end{array}$ & $\begin{array}{l}\text { Valor } \\
\text { Doação } \\
2010\end{array}$ & $\begin{array}{c}\text { valor } \\
\text { Doação } \\
\text { Presiden } \\
\text { cial }\end{array}$ & $\begin{array}{l}\text { Valor } \\
\text { Doação } \\
2012\end{array}$ \\
\hline Desconto & 1 & $-0.1871^{*}$ & $-0.1360 *$ & $-0.1345^{*}$ & $-0.1249 *$ & $-0.0837 *$ & $-0.0787^{*}$ \\
\hline Doação 2010 & $0.1871^{*}$ & 1 & $0.2922 *$ & $0.3939 *$ & $0.2004 *$ & $0.1628 *$ & 0.1 \\
\hline Doação Presidencial & $-0.1360^{*}$ & $0.2922 *$ & 1 & 0.0277 & $0.4241^{*}$ & $0.5571^{*}$ & $0.2685^{*}$ \\
\hline Doação 2012 & $-0.1345 *$ & $0.3939 *$ & 0.0 & 1 & $0.2230 *$ & $0.0810 *$ & $0.2005 *$ \\
\hline Região N & 0.0 & 0.0 & 0.0 & 0.0 & -0. & 0.0006 & -0 . \\
\hline Região SE & 0.1568 * & $-0.1754 *$ & $-0.0686 *$ & $0.0767 *$ & -0.0404 & -0.054 & 0.002 \\
\hline Região NE & 0. & 0.05 & $0.0678 *$ & -0.6 & 0.0 & 0.0449 & 0.0 \\
\hline Região $S$ & $5 *$ & 0.0 & -0 . & -0 . & 0.0 & 0.0 & 0.0 \\
\hline Região co & $-0.1167 *$ & -0.0 & -0.1 & -0.0 & -0.0 & -0.0 & -0 . \\
\hline Ano 2007 & 0.1 & 0.07 & 0.1 & 0.07 & 0.0179 & 0.0 & -0 . \\
\hline Ano 2008 & $89 *$ & 0.0 & 0.0 & -0.0 & -0.1 & 0.00 & -0 . \\
\hline Ano 2009 & $1 *$ & 0.0 & 0.2 & 0.0 & 0.1 & 0.1 & 0.1 \\
\hline Ano 2010 & -0.1 & $0.0720 *$ & 0.0571 & 0.004 & 0.0 & 0.04 & -0 . \\
\hline Ano 2011 & & -0 . & -0. & -0. & -0 . & -0.6 & -0 . \\
\hline Ano 2012 & 0.1 & -0.0 & -0.1 & -0.0 & -0.0 & -0.0 & -0 . \\
\hline Ano 2013 & -0.0274 & -0.0 & $-0.1279 *$ & -0.0277 & -0. & $-0.0712 *$ & -0.0383 \\
\hline Valor Doação 2010 & $-0.1249 *$ & $0.2004 *$ & $0.4241^{*}$ & $0.2230^{*}$ & 1 & $0.9247^{*}$ & $0.8944^{*}$ \\
\hline Valor Doação Pres & -0.0 & 0.1 & 0.5 & 0.0 & 0.9 & 1 & 0.8 \\
\hline Valor Doação 2012 & 87 * & 0.1 & 0.2 & 0.2 & 0.8 & 0.84 & 1 \\
\hline Lei 8666/1993 & -0 & 0.0 & 0.2 & 0. & 0.1 & 0.1 & 0.0 \\
\hline Licitado Sede Dnit & $33 *$ & 0.1 & 0.0 & 0.1 & 0.1 & 0.0 & 0.0 \\
\hline Licitantes & 0.6634 * & $-0.0958^{*}$ & $-0.1426^{*}$ & $-0.0953^{*}$ & $-0.0928 *$ & $-0.0927 *$ & -0.0554 \\
\hline Q1icitantes & $0.5755^{*}$ & $-0.1089 *$ & $-0.1200 *$ & $-0.0840^{*}$ & $-0.0802 *$ & $-0.0760 *$ & -0.0492 \\
\hline Grupo 1 & $-0.4793 *$ & $0.0860 *$ & $0.2086^{*}$ & $0.1151^{*}$ & $0.2075 *$ & $0.1610 *$ & $0.1640 *$ \\
\hline Grupo 2 & -0.2 & $0.1323^{*}$ & $-0.1106 *$ & 0.0421 & -0.0 & $-0.0922 *$ & -0.0 \\
\hline Grupo 3 & $0.7597 *$ & $-0.2209 *$ & $-0.0862 *$ & $-0.1551^{*}$ & $-0.1099 *$ & $-0.0594 *$ & $-0.0748^{*}$ \\
\hline Lotes & $-0.1087^{*}$ & 0.1913 * & $0.0692 *$ & $0.0990 *$ & $0.0658^{*}$ & 0.0398 & $0.0706^{*}$ \\
\hline Num. Contratos & $0.2395^{*}$ & $0.3196^{*}$ & $0.2928^{*}$ & $0.2392 *$ & 0.0343 & $0.1271^{*}$ & -0.0156 \\
\hline Aditivos & $0.1260 *$ & -0.0089 & 0.0397 & 0.037 & 0.0201 & 0.0217 & 0.0258 \\
\hline Valor do Edital & $-0.2914 *$ & $0.1862 *$ & $0.2002 *$ & $0.1573^{*}$ & $0.3864 *$ & $0.3328 *$ & $0.2935 *$ \\
\hline Total Ativo & -0.0322 & 0.0373 & 0.0214 & -0.0104 & 0.0289 & 0.0316 & 0.0246 \\
\hline \multicolumn{8}{|c|}{ ficativas a $5 \%$} \\
\hline
\end{tabular}

\section{Fonte: elaboração do autor}

Ao analisar os resultados da Tabela 3 - Correlações das variáveis do modelo, destaca-se que as empresas que realizaram doações a campanhas participaram das licitações em um ambiente menos competitivo, ou seja, com menos licitantes. Tal fato é confirmado pela correlação negativa e significativa entre empresas doadoras de campanha e número de 
licitantes participantes do certame. Essa constatação está alinhada com os resultados do estudo de Rumba e Jasčišens (2009), no qual os autores afirmam que as empresas politicamente conectadas participam de licitações em ambientes com até $20 \%$ menos concorrência e em processos licitatórios menos transparentes. Coviello e Gagliarducci, (2010) também verificaram ambientes de menor concorrência quando da participação de empresas politicamente conectadas.

Outra constatação é a correlação positiva entre número de contratos e empresas doadoras de campanha. Ou seja, empresas doadoras de campanha conseguem mais contratos com o poder público. Isso pode ser constatado pela correlação significativa e positiva entre as variáveis dummies que identificam empresas doadoras e número de contratos com o poder público. Essa verificação está alinhada com os resultados obtidos no trabalho de (Boas, Hidalgo e Richardson (2014). No mesmo sentido são os trabalhos de Goldman, Rocholl e So, (2008) e Coviello e Gagliarducci, (2010) que também constataram um aumento no número de contratos para empresas politicamente conectadas.

Ressalta-se também a forte correlação positiva entre o desconto das licitações e a variável que indica que a licitação foi realizada no ano de 2011. O principal fato relevante ocorrido no âmbito do DNIT durante o ano de 2011 é a mudança do comando do Ministério dos Transportes e do DNIT, devido à denúncia de corrupção que assolou o Ministério dos Transportes e o DNIT ${ }^{10}$. Fazendo-se um paralelo com a literatura, pode-se admitir que no ano de 2011 as conexões políticas foram temporariamente rompidas, o que resultou em quebra da situação até então vigente. Além disso, a forte cobertura desse fato pela imprensa pode ter induzido maior cautela dos gestores e das empresas nas contratações ocorridas nesse período.

Relata-se, ainda, a forte correlação entre as variáveis independentes que retratam o volume de recurso doado pelas empresas às campanhas políticas nos anos de 2010 e 2012. Isso indica que a distribuição de doações nos anos de 2010 e 2012 praticamente não se alterou. O volume total de recurso tem magnitudes diferentes, mas guarda a mesma distribuição, o que pode indicar uma relação duradoura e estável entre empresas doadoras e políticos, constatação que vai ao encontro dos estudos de Samuels (2001) e Boas, Hidalgo e Richardson (2014).

\footnotetext{
${ }^{10} \mathrm{http}$ ://www1.folha.uol.com.br/poder/2011/07/945936-veja-a-cronologia-da-crise-no-ministerio-dostransportes.shtml
} 
Cumpre mencionar a forte correlação positiva entre número de licitantes e o desconto obtido na licitação. De acordo com Bower, (1993) e a própria teoria dos leilões, um aumento do número de licitantes tende a anular as ineficiências das formas de contratação, de forma a aumentar os ganhos do governo (leiloeiro).

Por fim, nota-se a ausência de correlação significativa entre o "total dos ativos" e o desconto obtido na licitação. Neste estudo, a variável "total dos ativos" tem o objetivo de ser uma proxy para o custo das empresas. Isso porque empresas maiores (com mais ativos), que detém maior número de contratos, têm, a princípio, maior know how, maior acesso a crédito bancário, e maior poder de barganha com fornecedores, enfim, um custo menor para execução de obras. De acordo com Bower, (1993) e a teoria dos leilões, era de se esperar que o desconto ofertado pelas empresas licitantes em um ambiente competitivo fosse proporcional à sua estrutura de custos, o que não foi verificado. De duas, uma: ou o ambiente não é competitivo ou a proxy utilizada neste estudo não é adequada para refletir a estrutura de custo das empresas.

\subsection{Resultados obtidos pelo Método de Estimação}

Propôs-se estimar os três modelos retro citados pelo método dos mínimos quadrados ordinários (MQO) em seção cruzada. O resultado da estimação está representado na Tabela 4 - Resultados da estimação do modelo econométrico. Repisa-se o modelo econométrico proposto:

(1) desconto $=B_{0}+B_{1-3} *($ doações $)+B_{4-7} *($ regiões $)+B_{8-13} *($ anos $)+B_{17-28} *($ controle $)+u$

(2) desconto $=\mathbf{B}_{0}+\mathbf{B}_{4-7} *($ regiões $)+\mathbf{B}_{8-13} *($ anos $)+B_{14-16} *($ valores doações $)+B_{17-28} *($ controle $)+u$

(3) desconto $=\mathbf{B}_{0}+\mathbf{B}_{1-3} *($ doações $)+\mathbf{B}_{4-7} *($ regiões $)+\mathbf{B}_{8-13} *($ anos $)+\mathbf{B}_{14-16} *($ valores doações $)+\mathbf{B}_{17-28} *($ controle $)+\mathbf{u}$ 
Tabela 4 - Resultados da estimação do modelo econométrico

\begin{tabular}{|c|c|c|c|}
\hline & $\begin{array}{r}(1) \\
\text { Desconto }\end{array}$ & $\begin{array}{r}(2) \\
\text { Desconto }\end{array}$ & $\begin{array}{r}(3) \\
\text { Desconto }\end{array}$ \\
\hline Doacao2010 & $\begin{array}{l}-0.965^{*} \\
(0.521)\end{array}$ & & $\begin{array}{l}-0.942 * \\
(0.526)\end{array}$ \\
\hline Doacaopres & $\begin{array}{l}-1.189 * \\
(0.658)\end{array}$ & & $\begin{array}{l}-1.413^{* *} \\
(0.704)\end{array}$ \\
\hline Doacao2012 & $\begin{array}{l}-1.502^{* * *} \\
(0.477)^{-1}\end{array}$ & & $\begin{array}{l}-1.577^{* * *} \\
(0.520)\end{array}$ \\
\hline Regiaose & ${ }^{2.366^{* * *}}$ & $\begin{array}{l}2.257^{* * *} \\
(0.715)^{2}\end{array}$ & $\begin{array}{l}2.344^{* * * *} \\
(0.723)^{2}\end{array}$ \\
\hline Regiaone & $\begin{array}{l}1.970^{* * *} \\
(0.679)^{2}\end{array}$ & ${ }^{1.836^{* * *}}$ & $\begin{array}{l}1.944 * * * \\
(0.684)\end{array}$ \\
\hline Regiaos & $\begin{array}{l}-1.143 \\
(0.735)\end{array}$ & $\begin{array}{l}-1.425^{*} \\
(0.745)\end{array}$ & $\begin{array}{l}-1.183 \\
(0.746)\end{array}$ \\
\hline Regiaoco & $\begin{array}{l}-4.365^{* * *} \\
(0.797)^{2}\end{array}$ & $\begin{array}{l}-4.396^{* * *} \\
(0.804)\end{array}$ & $\begin{array}{l}-4.391 * * * \\
(0.799)\end{array}$ \\
\hline ano2007 & $(2.131)^{10.63^{* * *}}$ & $(2.225)^{10.29 * * *}$ & $(2.132)^{10.66^{* * *}}$ \\
\hline ano2008 & $\begin{array}{l}-1.444^{*} \\
(0.852)\end{array}$ & $\begin{array}{l}-1.431^{*} \\
(0.865)\end{array}$ & $\begin{array}{l}-1.440^{*} \\
(0.855)\end{array}$ \\
\hline ano2009 & $\begin{array}{l}-1.366^{*} \\
(0.772)\end{array}$ & $\begin{array}{l}-1.491^{*} \\
(0.781)\end{array}$ & $\begin{array}{l}-1.396^{*} \\
(0.781)\end{array}$ \\
\hline ano2011 & $\begin{array}{l}5.454^{* * *} \\
(0.967)^{-1}\end{array}$ & $(0.981)^{5.512^{* * *}}$ & ${ }^{5.449 * * *}$ \\
\hline ano2012 & $\begin{array}{l}6.940^{* * *} \\
(0.886)\end{array}$ & $\begin{array}{l}7.094^{* * *} \\
(0.899)\end{array}$ & $\begin{array}{l}6.905 * * * \\
(0.887)^{2}\end{array}$ \\
\hline ano2013 & $(1.326)^{3.682 * * *}$ & $(1.336)^{3.898 * *}$ & $(1.330)^{3.668 * *}$ \\
\hline Lei 8666 & $\begin{array}{l}5.452^{* * *} \\
(0.902)^{2}\end{array}$ & $\begin{array}{l}5.336 * * * \\
(0.903)\end{array}$ & $\left(^{5.415^{* * * *}}\right.$ \\
\hline Licitadosede & $\begin{array}{l}1.954^{* * *} \\
(0.611)^{2}\end{array}$ & $\begin{array}{l}1.762^{* * *} \\
(0.609)\end{array}$ & $\begin{array}{l}1.950^{* * *} \\
(0.611)\end{array}$ \\
\hline Licitantes & $(0.124)^{1.661^{* * *}}$ & $\begin{array}{l}1.678^{* * * *} \\
(0.123)^{-1}\end{array}$ & $\begin{array}{l}1.659 * * * \\
(0.124)^{2}\end{array}$ \\
\hline Q1icitantes & $(0.00448)^{-0.0282^{* * *}}$ & 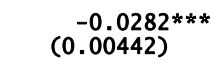 & 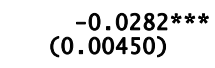 \\
\hline Grupo 2 & $\begin{array}{l}2.875^{* * *} \\
(0.576)\end{array}$ & $\begin{array}{l}2.997 * * * \\
(0.572)\end{array}$ & $(0.579)^{2.871 * * *}$ \\
\hline Grupo 3 & $\begin{array}{l}19.57^{* * *} \\
(0.849)^{-}\end{array}$ & $(0.857)^{19.93^{* * *}}$ & $\begin{array}{l}19.53^{* * * *} \\
(0.855)^{-1}\end{array}$ \\
\hline Lotes & $\begin{array}{l}-1.521^{* * *} \\
(0.462)\end{array}$ & $\begin{array}{l}-1.730^{* * *} \\
(0.468)\end{array}$ & $\begin{array}{l}-1.535 * * * \\
(0.467)\end{array}$ \\
\hline NumContratos & $\begin{array}{l}0.0457^{* * *} \\
(0.00814)^{2}\end{array}$ & ${ }^{0.0281^{* * * *}}$ & $\begin{array}{l}0.0462^{* * *} \\
(0.00851)^{2}\end{array}$ \\
\hline Aditivos & $\begin{array}{c}0.00866 \\
(0.0110)\end{array}$ & $\begin{array}{r}0.0102 \\
(0.0111)\end{array}$ & $\begin{array}{c}0.00843 \\
(0.0110)\end{array}$ \\
\hline V1rEdital & $\begin{array}{r}0.00404 \\
(0.00289)\end{array}$ & $\begin{array}{r}0.00183 \\
(0.00312)\end{array}$ & $\begin{array}{r}0.00325 \\
(0.00312)\end{array}$ \\
\hline TotalAtivo & $\begin{array}{l}0.00000997 * * * \\
(0.00000356)\end{array}$ & $\begin{array}{l}0.00000943 * * * \\
(0.00000353)\end{array}$ & $\begin{array}{l}0.00000946 * * * \\
(0.00000358)\end{array}$ \\
\hline v1rDoac2010 & & $\begin{array}{l}-0.189 * \\
(0.104)\end{array}$ & $\begin{array}{l}0.00295 \\
(0.113)\end{array}$ \\
\hline v1rDoacPres & & $\begin{array}{r}0.656 \\
(0.656)\end{array}$ & $\begin{array}{r}0.0837 \\
(0.722)\end{array}$ \\
\hline V1rDoac2012 & & $\begin{array}{r}0.0748 \\
(0.0868)\end{array}$ & $\begin{array}{r}0.0327 \\
(0.0829)\end{array}$ \\
\hline Constant & ${ }^{-8.151^{* * *}}$ & $\begin{array}{l}-8.905^{* * *} \\
(1.439)\end{array}$ & $\begin{array}{l}-8.033^{* * *} \\
(1.434)\end{array}$ \\
\hline $\begin{array}{l}\text { observations } \\
\text { R-squared } \\
\text { Adjusted R-squared }\end{array}$ & $\begin{array}{l}1107 \\
0.817 \\
0.813\end{array}$ & $\begin{array}{l}1107 \\
0.814 \\
0.810\end{array}$ & $\begin{array}{l}1107 \\
0.817 \\
0.812\end{array}$ \\
\hline
\end{tabular}

Standard errors in parentheses

* $p<0.10$, ** $p<0.05, * * * p<0.01$

Fonte: elaboração do autor 
Os resultados obtidos demonstram que o primeiro modelo apresentou $\mathrm{R}^{2}$ ajustado de $81,3 \%$, o segundo modelo, $\mathrm{R}^{2}$ de $81,0 \%$ e o terceiro $\mathrm{R}^{2}$ de $81,2 \%$. A estatística $\mathrm{F}$ dos modelos foram, respectivamente: 353,81; 310,95 e 305,6. Portanto, rejeita-se a hipótese de todos os coeficientes serem nulos a um nível de significância de $1 \%$.

Cumpre mencionar que também se rejeita a hipótese de que as variáveis dummies "doações" e as variáveis "valores de doações" não tem efeito conjunto sobre o desconto nas licitações, a um nível de significância de $1 \%$, ou seja, as variáveis relacionadas às doações de campanha impactam na variação do preço das obras públicas licitadas, conforme disposto na Tabela 5 - Teste F doações.

Tabela 5 - Teste F doações

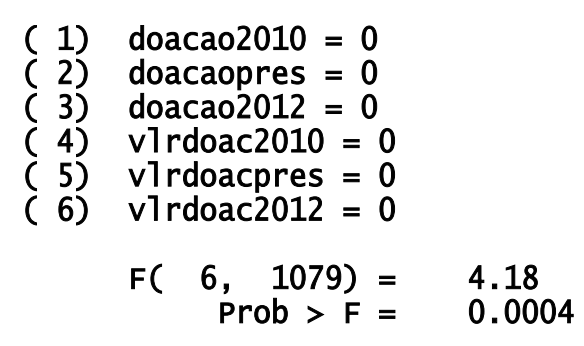

Fonte: elaboração do autor

Os resultados dos modelos quanto às variáveis de controle são similares àquele proposto por Faria, Ferreira e Santos, (2010), sendo o $\mathrm{R}^{2}$ do modelo proposto em seu trabalho de 67,4\%. Passa-se agora a interpretar os dados da Tabela 4 - Resultados da estimação do modelo econométrico.

\subsubsection{Doações a campanhas eleitorais}

Nas licitações públicas, as empresas oferecem desconto em relação ao preço de referência da Administração (preço reserva) para conseguir contratar. As licitações vencidas pelas empresas doadoras de campanha apresentaram desconto inferior às licitações vencidas pelas empresas não doadoras, conforme dados da Tabela 4 - Resultados da estimação do modelo econométrico. Essa diferença entre o desconto ofertado pelas empresas doadoras e não doadoras é de aproximadamente 1\% em relação ao preço de referência da Administração, a um nível de significância de $10 \%$ nos modelos 1 e 3 . Essa constatação é válida para as doações ocorridas nos anos de 2010 para os candidatos aos cargos de governador, deputado e 
senador. Cumpre mencionar que não se realizou distinção entre os partidos, visto que o Brasil é governado pelo sistema presidencialismo de coalização, no qual vários partidos de fato participam do governo. Além disso, não se diferenciou doações a candidatos eleitos e não eleitos.

Conforme Tabela 2 - Resumo das estatísticas das variáveis, $62 \%$ das obras foram contratadas com empresas doadoras aos candidatos aos cargos de governador, deputado e senador. Isso mostra significativo interesse das empresas nas conexões políticas com candidatos a esses cargos.

Já no caso das empresas que realizaram doações aos candidatos à presidência da república, verificou-se que, conforme Tabela 2 - Resumo das estatísticas das variáveis, 12\% dos contratos do DNIT no período avaliado foram contratados com essas empresas. Nesses casos, consideraram-se apenas as doações efetuadas ao candidato e ao partido que saíram vitoriosos na corrida presidencial de 2010. De acordo com os dados da Tabela 4 - Resultados da estimação do modelo econométrico, as licitações vencidas pelas empresas doadoras para campanha presidencial também apresentaram desconto inferior às licitações vencidas pelas empresas não doadoras. Essa diferença entre o desconto ofertado pelas empresas doadoras e não doadoras foi de 1,4\% (significância de 5\%) em relação ao preço de referência, para o modelo 3. Já no modelo 1, esse percentual foi de 1,2\%, (significância de 10\%).

Para as empresas que contribuíram para as campanhas dos candidatos aos cargos de prefeito e de vereador no ano de 2012, constatou-se que, conforme Tabela 2 - Resumo das estatísticas das variáveis, $32 \%$ dos contratos do DNIT no período avaliado foram contratados com essas empresas. Nesses casos, consideraram-se doações aos partidos e aos prefeitos diretamente, sem distinção entre candidatos eleitos e não eleitos. Doações diretas aos vereadores foram excluídas devido à baixa probabilidade desses políticos influenciarem na gestão do DNIT, que é federal. Da mesma forma dos casos anteriores, as licitações vencidas pelas empresas doadoras de campanha também apresentaram desconto inferior às licitações vencidas pelas empresas não doadoras. Essa diferença entre o desconto ofertado pelas empresas doadoras e não doadoras foi de $1,5 \%$ em relação ao preço de referência da Administração, a um nível de significância de 1\% nos modelos 1 e 3 .

A partir dessas constatações, verifica-se que de fato as licitações vencidas pelas empresas doadoras de campanha apresentaram desconto inferior às licitações vencidas pelas 
empresas não doadoras. Entretanto, fica a pergunta: como as empresas doadoras conseguem essa vantagem em relação às empresas não doadoras?

Conforme citam os autores Santos, Machado e Rocha, (1997), não é incomum a proposta vencedora de uma obra ter sido escolhida antes de o orçamento federal ter sido aprovado. Considerando que as obras são contratadas por meio de licitação, por certo haveria no mínimo uma das três situações: ou há um cartel de empresas doadoras de campanha atuantes, ou há algum tipo de direcionamento na licitação, consubstanciado, por exemplo, por restrições à competitividade, ou ainda existem ambas as situações ao mesmo tempo.

Para avaliar a hipótese de existência de cartéis, recorre-se ao estudo realizado por Porter e Zona, (1993). Esses autores verificaram que nas licitações de obras públicas realizadas no Estado de Nova Iorque havia a presença de cartéis. Os autores identificaram a presença de lances fantasmas, que não guardavam correlação com o custo das empresas cartelizadas. É que pela teoria dos leilões, os lances das empresas deveriam ser proporcionais aos seus custos em um ambiente competitivo. Por outro lado, empresas fora do cartel davam lances proporcionais à sua estrutura de custos, conforme prevê a teoria.

No presente estudo, conforme dados da Tabela 4 - Resultados da estimação do modelo econométrico, verificou-se que a proxy utilizada para o custo das empresas: "total do ativo" não explica de forma consistente o desconto obtido nas licitações. Pois, apesar do coeficiente da variável ser positivo e significante a $1 \%$, esse coeficiente é extremamente baixo, da ordem de $10^{-5}$ por milhão de ativo das empresas. Em outras palavras, baixo poder explicatório da variável desconto.

Isso pode ser um indicativo de que os lances das empresas não guardam correlação com seu custo, ou seja, indicativo da existência de cartel, em raciocínio similar ao empregado por Porter e Zona, (1993) e também preconizado pela teoria dos leilões.

Outra hipótese para o baixo poder explicatório da proxy para os custos das empresas é a sua possível inadequação. No entanto, observa-se que o sinal positivo e significativo dessa proxy é consistente com o que preconiza a teoria econômica, pois quanto maior o "total do ativo" (ou o menor custo das empresas), maior é o desconto nas licitações, ou seja, o sinal econômico positivo e significativo da proxy enfraquece a hipótese de sua inadequação.

Cumpre mencionar que neste estudo testaram-se outras proxys para o custo/tamanho das empresas: "ativo circulante", "passivo circulante", "ativo total", "passivo 
total" e "patrimônio líquido" das empresas. A proxy "patrimônio líquido" foi descartada porque mais da metade das empresas possuíam patrimônio líquido zero, além disso a variável não possuía significância estatística. As proxys "ativo e passivo circulante" não são significantes a $10 \%$. As proxys ativo e passivo total são significantes, com resultados semelhantes no modelo econométrico. Assim, optou-se por incluir o ativo total das empresas como proxy para a estrutura de custo/tamanho das empresas. Ressalta-se ainda que o valor da variável total do ativo se refere à posição das empresas para o ano de 2013. Sugere-se em futuros estudos avaliar a correlação entre a evolução patrimonial das empresas e suas ligações políticas.

Apesar disso, cumpre registrar que não se logrou provar, de fato, a presença de cartéis neste estudo, mas apenas um indício de sua existência, baseado na literatura sobre o tema e na literatura sobre leilões. Por outro lado, ressalta-se que existem relatos de que essa prática de cartelização de empreiteiras já ocorreu no Brasil. Krieger, Rodrigues e Bonassa, (1994) relataram a existência de cartéis de empreiteiras brasileiras doadoras de campanha que atuaram no esquema de corrupção conhecido por "Anões do Orçamento". Mais recentemente, delatores da operação Lava-Jato da Polícia Federal afirmaram que obras da Petrobrás e de outros entes públicos, inclusive setores de infraestrutura rodoviária, eram contratados por meio de um cartel de empreiteiras ${ }^{11}$ doadoras de campanha. Cumpre relatar que a presença de atuação de cartéis implica maior preço de contratação, ou seja, menor desconto nas licitações.

Passa-se agora a discorrer sobre a possibilidade de restrição à competitividade como forma de direcionamento de licitações às empresas doadoras de campanha. Os resultados encontrados nos estudos de Rumba e Jasčišens (2009) apontam que na Letônia, empresas politicamente conectadas participaram de licitações públicas em um ambiente com $20 \%$ menos concorrência em relação às empresas que não possuíam ligações políticas. Além disso, os autores mostraram que a possível fonte da diminuição da concorrência devia-se às especificações técnicas tendenciosas.

No mesmo sentido, constatou-se no presente estudo, conforme Tabela 3 Correlações das variáveis do modelo, que as empresas doadoras de campanha participaram de licitações com menor concorrência. Além disso, de acordo com resultados das auditorias do Tribunal de Contas da União, entre os anos de 2007 e 2013, dispostos na Tabela 6 - Restrição à Competitividade, há 33 achados que relatam a ocorrência dessa restrição nas licitações de

${ }^{11} \mathrm{http}: / /$ veja.abril.com.br/noticia/brasil/esquema-na-petrobras-envolvia-cartel-de-empreiteiras-dizcosta 
obras públicas a cargo do DNIT. Dito de outra forma, a restrição à competitividade pode ter contribuído para o direcionamento das licitações às empresas doadoras de campanha, fazendo com que elas conseguissem contratar com o poder público ofertando menores descontos quando comparadas às empresas não doadoras.

Cumpre mencionar que a restrição à competitividade só seria possível por meio de participação de agentes públicos do DNIT na montagem dos editais de licitação. Em outras palavras, a empreiteira realizaria a doação ao candidato, estabelecendo sua conexão política; o candidato, para defender os interesses da empresa que o beneficiou teria que atuar no âmbito do poder executivo para retribuir o investimento da empresa doadora por meio de benefícios em contratos públicos, conforme mecanismo descrito no trabalho de Boas, Hidalgo e Richardson (2014). 
Tabela 6 - Restrição à Competitividade

\begin{tabular}{|c|c|c|c|c|}
\hline Processo & uF & obra & Situação encontrada & Ano \\
\hline $307 / 2007-9$ & $\mathrm{RN}$ & $\begin{array}{l}\text { (PAC) } \text { BR-101/RN - } \text { Adequação } \\
\text { Trecho Natal - Divisa RN/PB } \\
\end{array}$ & Restrição ao caráter competitivo da licitação & 2007 \\
\hline $012.121 / 2007-6$ & AM & $\begin{array}{l}\text { (PAC) BR-319/AM - Construção } \\
\text { Divisa RO/AM - Manaus }\end{array}$ & Restrição ao caráter competitivo da licitação & 2007 \\
\hline $013.261 / 2007-1$ & MA & $\begin{array}{l}\text { (PAC) BR-316/MA-Recuperação } \\
\text { Div. PA/MA-Entr. BR-226/343 (Div. } \\
\text { MA/PI) }\end{array}$ & Restrição ao caráter competitivo da licitação & 2007 \\
\hline $016.214 / 2007-5$ & $A C$ & $\begin{array}{l}\text { (PAC) BR-364/AC-Construção Sena } \\
\text { Madureira - Cruzeiro do sul }\end{array}$ & Restrição ao caráter competitivo da licitação & 2007 \\
\hline $016.972 / 2007-7$ & MT & $\begin{array}{llll}\begin{array}{l}\text { (PAC) } \\
\text { MT/PA }\end{array} & \text { BR-163 Divisa MS/MT - } \\
\end{array}$ & Restrição ao caráter competitivo da licitação & 2007 \\
\hline $006.042 / 2008-3$ & $A C$ & $\begin{array}{l}\text { (PAC) BR-364/AC-Construção Sena } \\
\text { Madureira - Cruzeiro do Sul }\end{array}$ & $\begin{array}{l}\text { Restrição ao caráter competitivo da licitação } \text { - Infração } \\
\text { aos Princípios da Razoabilidade Moralidade da Isonomia } \\
\text { entre os Licitantes e/ou ao princípio do Julgamento } \\
\text { objetivo decorrente de interposição ilegal de recursos e } \\
\text { inabilitação injusta de licitante. }\end{array}$ & 2008 \\
\hline $006.415 / 2008-8$ & PA & $\begin{array}{l}\text { (PAC) BR-230/PA Construção Marabá } \\
\text { - A1tamira - Itaituba/, Ane1 } \\
\text { Viário de Itaituba }\end{array}$ & \begin{tabular}{|l|l} 
Restrição ao caráter competitivo da licitação - Escolha de \\
proposta diferente da mais vantajosa para a Administração \\
Pública decorrente de exigência descabida de comprovantes \\
técnicos índices econômico-contábeis e da falta de \\
critérios objetivos de qualificação e aceitabilidade das \\
propostas.
\end{tabular} & 2008 \\
\hline $007.287 / 2008-0$ & RJ & \begin{tabular}{|l} 
(PAC) Construção Arco Rodoviário \\
/ RJ - Entr. BR-101(Su1) C/ \\
Acesso ao Porto de Sepetiba \\
Entr. BR-493 C/BR 101 (Norte)
\end{tabular} & $\begin{array}{l}\text { Restrição ao caráter competitivo da licitação - Escolha de } \\
\text { proposta diferente da mais vantajosa para a Administração } \\
\text { Pública decorrente de exigência descabida de comprovantes } \\
\text { técnicos índices econômico-contábeis e da da falta de } \\
\text { critérios objetivos de qualificação e aceitabilidade das } \\
\text { propostas. }\end{array}$ & 2008 \\
\hline $007.287 / 2008-0$ & RJ & 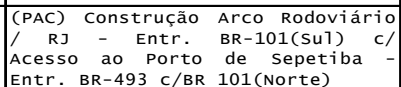 & $\begin{array}{l}\text { Restriça ao caráter competitivo da licitação - Escolha de } \\
\text { proposta diferente da mas vantajosa para a Administração } \\
\text { Pública em decorrência da subjetividade de critérios de } \\
\text { habilitacão e julgamento das propostas. }\end{array}$ & 2008 \\
\hline $007.287 / 2008-0$ & RJ & \begin{tabular}{|l} 
(PAC) Construção Arco Rodoviário \\
/ RJ - Entr. \\
Acesso ao PR-101(Sul) \\
Acerto de Sepetiba \\
Entr. BR-493 C/BR 101 (Norte) \\
\end{tabular} & $\begin{array}{l}\text { Restricão ao caráter competitivo da licitação } \\
\text { Inexistência de publicação do aviso de edital ou publicação } \\
\text { do aviso do edital sem respeitar o prazo mínimo previsto na } \\
\text { Lei 8.666/93. }\end{array}$ & 2008 \\
\hline $007.287 / 2008-0$ & RJ & $\begin{array}{l}\text { (PAC) Construção Arco Rodoviário } \\
\text { / RJ - Entr. } \\
\text { Acesso ao Porto de Sepetiba } \\
\text { Entr. BR-493 c/BR } 101 \text { (Norte) }\end{array}$ & $\begin{array}{l}\text { Restrição ao caráter competitivo da licitação - Processo } \\
\text { licitatório direcionado em decorrência de restrição de } \\
\text { competitividade. }\end{array}$ & 2008 \\
\hline $010.506 / 2008-0$ & MG & $\begin{array}{l}\text { (PAC) BR-365/MG - Duplicação } \\
\text { Entr. BR-050 - Entr.BR-153 }\end{array}$ & $\begin{array}{l}\text { Restrição ao caráter competitivo da licitação - Restrição } \\
\text { ao caráter competitivo da licitação decorrente de exigência } \\
\text { descabida de comprovantes técnicos indices econômicos } \\
\text { contábeis e da falta de critérios objetivos de qualificação } \\
\text { e aceitabilidade das propostas. }\end{array}$ & 2008 \\
\hline $013.349 / 2008-0$ & MT & \begin{tabular}{|l} 
(PAC) BR-364/MT \\
Diamantino - Sapeza1 -
\end{tabular} & $\begin{array}{lllll}\text { Demais falhas no processo licitatório } & \text { Restrição a } \\
\text { caráter competitivo da licitação em virtude da fixação de } \\
\text { número mínimo de atestados exigência desarrazoada de } \\
\text { comprovantes técnicose índices econômicos. } & & \\
\end{array}$ & 2008 \\
\hline $019.160 / 2008-4$ & RO & $\begin{array}{l}\text { (PAC) BR-364 - Recuperação de } \\
\text { Trechos Rodoviários - Divisa } \\
\text { MT/RO - Divisa RO/AC }\end{array}$ & $\begin{array}{l}\text { Restrição ao caráter competitivo da licitação - } \text { Infração } \\
\text { aos princípios da Razoabilidade Moralidade da Isonomia } \\
\text { entre os Licitantes e/ou ao Princípio do Julgamento } \\
\text { objetivo decorrente de interposição ilegal de recursos e } \\
\text { inabilitação injusta de licitante. }\end{array}$ & 2008 \\
\hline $005.656 / 2009-5$ & PA & 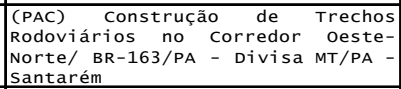 & $\begin{array}{l}\text { Restrição a competitividade da licitação dec } \\
\text { critérios inadequados de habilitação e julgamento }\end{array}$ & 2009 \\
\hline $005.868 / 2009-7$ & MT & $\begin{array}{l}\text { (PAC) Manutenção de } \\
\text { Rodoviários na BR-163/MT }\end{array}$ & $\begin{array}{l}\text { Restrição a competitividade da licitação dec } \\
\text { critérios inadequados de habilitação e julgamento }\end{array}$ & 2009 \\
\hline $005.870 / 2009-5$ & MT & $\begin{array}{l}\text { (PAC) Manutenção de } \\
\text { Rodoviários na BR-364/MT }\end{array}$ & $\begin{array}{l}\text { Restrição a competitividade da licitação decorrente de } \\
\text { critérios inadequados de habilitação e julgamento. }\end{array}$ & 2009 \\
\hline $006.266 / 2009-4$ & $\mathrm{PE}$ & 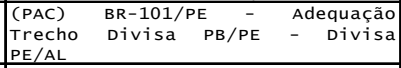 & $\begin{array}{l}\text { Restrição a competitividade da licitação decorrente de } \\
\text { critérios inadequados de habilitação e julgamento. }\end{array}$ & 2009 \\
\hline $007.513 / 2009-1$ & RJ & $\begin{array}{|llll|}\text { (PAC) } & \text { Construção } & \text { Arco Rodoviário } \\
\text { / RJ - Entr. } & \text { BR-101(SuT) C/ } \\
\text { Acesso ao Porto de Sepetiba } & - \\
\text { Entr. BR-493 C/BR } & 101 \text { (Norte) } \\
\end{array}$ & $\begin{array}{l}\text { Restrição a competitividade da licitação de } \\
\text { critérios inadequados de habilitação e julgamentc }\end{array}$ & 2009 \\
\hline $011.341 / 2009-1$ & RJ & $\begin{array}{l}\text { (PAC) BR-101/RJ - Adequação Santa } \\
\text { Cruz - Itacurussá - Mangaratiba }\end{array}$ & $\begin{array}{l}\text { Restrição a competitividade da } 1 \\
\text { critérios inadequados de habilitação }\end{array}$ & 2009 \\
\hline $012.716 / 2009-5$ & Tо & \begin{tabular}{|l} 
Adequação de \\
na BR-153/TO
\end{tabular} & $\begin{array}{l}\text { Restrição a competitividade da licitação decorrente de } \\
\text { critérios inadequados de habilitação e julgamento. }\end{array}$ & 2009 \\
\hline $007.496 / 2010-9$ & AP & $\begin{array}{l}\text { (PAC) BR-156/AP - Construção } \\
\text { Ferreira Gomes - oiapoque }\end{array}$ & $\begin{array}{l}\text { Restrição a competitividade da licitação decorrente de } \\
\text { critérios inadequados de habilitação e julgamento. }\end{array}$ & 2010 \\
\hline $011.817 / 2010-0$ & PB & $\begin{array}{ll}\text { (PAC) } & \text { BR-101/PB } \\
\text { Divisa } & \text { PB/RN-Divisa } \\
\end{array}$ & $\begin{array}{l}\text { Restriça a competitividade da licitação decorrente } \\
\text { critérios inadequados de habilitação e julqamento. }\end{array}$ & 2010 \\
\hline $011.817 / 2010-0$ & PB & $\begin{array}{lcc}\text { (PAC) } & \text { BR-101/PB } & \text { - Adequação } \\
\text { Divisa } & \text { PB/RN-Divisa } & \text { PB-PE } \\
\end{array}$ & $\begin{array}{l}\text { Restrição a competitividade da licitação decorrente de } \\
\text { adocão indevida de pré-qualificação. }\end{array}$ & 2010 \\
\hline $014.920 / 2010-7$ & RJ & \begin{tabular}{|l} 
(PAC) Adequação de \\
Rodoviário - Entrochcamento \\
(Manilha) - Entroncamento \\
(Santa Guilhermina) - na BR-416 \\
no Estado do Rio de Janeiro \\
\end{tabular} & $\begin{array}{l}\text { Restrição a competitividade da } 1 i \\
\text { critérios inadequados de habilitação }\end{array}$ & 2010 \\
\hline $014.986 / 2010-8$ & PI & $\begin{array}{|lrrr|}\text { (PAC) Manutenção } & \text { de } & \text { Trechos } \\
\text { Rodoviários }- \text { na } & \text { BR-316 } & - & \text { no } \\
\text { Estado do Piauí } & & & \\
\end{array}$ & $\begin{array}{l}\text { Restrição a competitividade da licitação decorrente } \\
\text { critérios inadequados de habilitação e julgamento. }\end{array}$ & 2010 \\
\hline $015.254 / 2010-0$ & ES & 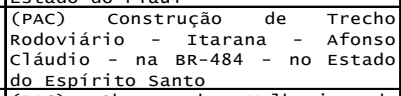 & $\begin{array}{l}\text { Restrição a competitividade da licitação decor } \\
\text { critérios inadequados de habilitação e julgamento. }\end{array}$ & 2010 \\
\hline $015.754 / 2010-3$ & RS & $\begin{array}{l}\text { (PAC) obras de MeThoria de } \\
\text { Capacidade, incluindo Duplicação } \\
\text { na Rodovia BR-386/RS }\end{array}$ & $\begin{array}{l}\text { Restrição a competitividade da licitação decorrente } \\
\text { critérios inadequados de habilitação e juigamento. }\end{array}$ & 2010 \\
\hline $030.105 / 2010-2$ & RS & $\begin{array}{l}\text { (PAC) BR-116/RS - Melhoria de } \\
\text { capacidade incluindo duplicação }\end{array}$ & $\begin{array}{l}\text { Restrição a competitividade da licitação decorrente } \\
\text { critérios inadequados de habilitação e julqamento. }\end{array}$ & 2011 \\
\hline $006.968 / 2012-0$ & $\mathrm{AC}$ & $\begin{array}{l}\text { Manutenção de Trecho Rodoviário } \\
\text { na BR-364/AC }\end{array}$ & $\begin{array}{l}\text { Restrição a competitividade da licitação decorrente de } \\
\text { adoção indevida de pré-qualificação. }\end{array}$ & 2012 \\
\hline $006.948 / 2013-8$ & AL & $\begin{array}{l}\text { (PAC) Adequação de Trecho } \\
\text { Rodoviário - Divisa AL/PE - } \\
\text { Divisa AL/SE-na BR-101/AL }\end{array}$ & $\begin{array}{l}\text { Restrição a competitividade da licitação decorrente } \\
\text { critérios inadequados de habilitação e julgamento. }\end{array}$ & 2013 \\
\hline $044.369 / 2012-3$ & MG & $\begin{array}{l}\text { Obras de duplicação da BR-381/MG } \\
\text { Lote } 4\end{array}$ & \begin{tabular}{|l} 
Restrição a competitividade da licitação decorrente de \\
critérios inadequados de habilitação e julgamento.
\end{tabular} & 2013 \\
\hline $004.434 / 2014-5$ & $\mathrm{PE}$ & $\begin{array}{l}\text { BR-101/PE - obras de implantação } \\
\text { do Anel viário de Recife }\end{array}$ & $\begin{array}{l}\text { Restrição a competitividade da licitação decorrente de } \\
\text { critérios inadequados de habilitação e julgamento. }\end{array}$ & 2014 \\
\hline
\end{tabular}




\subsubsection{Região centro-oeste e denúncias de corrupção}

Nesta seção, pretende-se avaliar se a existência de conexões entre políticos e agentes públicos do poder executivo tem influência sobre o desconto nas licitações de obras públicas. Mancuso (2007), afirma que o trabalho diário da mídia mostra que, em diversas esferas e instâncias, o poder público brasileiro é permeável a pressões empresariais pontuais em defesa de benefícios particulares, por meio de corrupção, conexões políticas dentre outras.

No caso particular do DNIT, a imprensa tem noticiado problemas na autarquia decorrente de indicações políticas para seus cargos. Muitas vezes, tais indicações são seguidas por denúncias de corrupção, conforme citação a seguir ${ }^{12}$.

\footnotetext{
Depois de comprar briga com o comando do PR ao fazer degolas no DNIT e no Ministério dos Transportes, a presidente Dilma Rousseff deve azedar a relação também com parlamentares que apadrinharam os dirigentes do órgão nos estados. Na próxima semana devem começar exonerações de superintendentes do Dnit que estão sob investigação e com problemas de gestão, e os padrinhos políticos desses gestores já manifestam insatisfação.
}

O Planalto já identificou que todas as 23 superintendências têm afilhados políticos em seus comandos, mesmo quando os dirigentes são técnicos, sendo que 12 são apadrinhados do PR. Mas as intervenções poderão ter como seus primeiros alvos indicados pelo PT, para não parecer perseguição ao PR.

Essa constatação de loteamento de cargos públicos entre os partidos é largamente abordada na literatura internacional, que de forma geral afirma que tais conexões políticas são mais comuns em países que possuem maior percepção da corrupção, onde as empresas obtêm maiores benefícios quando as conexões são mais fortes (Faccio, 2006). Conforme abordado anteriormente, o Brasil ocupa a posição $72^{\mathrm{a}}$ no ranking de corrupção. Em outras palavras, o Brasil pode ser considerado um país relativamente corrupto.

No presente trabalho, resolveu-se verificar a existência de ligações políticas relacionadas ao dirigente máximo do DNIT. Constatou-se que o diretor-geral da autarquia entre os anos de 2007 até 2011, que foi demitido da autarquia após denúncias de corrupção, era ligado a políticos do Estado do Mato Grosso ${ }^{13}$, sendo inclusive indicado por senador dessa região. Adicionalmente, a imprensa noticiou alguns episódios de envolvimento desse diretorgeral com a região centro-oeste: teria cobrado e obtido de um prefeito de Mato Grosso uma

\footnotetext{
$12 \mathrm{http}: / /$ oglobo.globo.com/politica/superintendencias-do-dnit-sao-loteadas-entre-partidos-nos-estadosmetade-do-pr-2710488

${ }^{13} \mathrm{http} / / /$ oglobo.globo.com/politica/pagot-entrega-carta-de-demissao-deixa-direcao-geral-do-dnit2711644
} 
casa em troca de benefícios ${ }^{14}$; e estava envolvido com denúncias de corrupção no Estado de Goiás $^{15}$.

A partir disso, resolveu-se estudar os descontos das obras públicas na região centro-oeste. Verificou-se que as licitações referentes à essa região, nos 3 modelos testados na Tabela 4 - Resultados da estimação do modelo econométrico apresentaram descontos inferiores às licitações da região norte do país (dummy da região norte ocultada nos modelos). A diferença entre esses descontos foi de aproximadamente $4,4 \%$ em relação ao preço de referência da Administração, nos 3 modelos (a um nível de significância de 1\%). Além disso, a região centro-oeste apresentou o menor desconto em relação a todas as outras regiões.

Buscou-se avaliar se os custos de construção da região centro-oeste seriam de fato superiores às demais regiões, o que poderia, de alguma forma, ajudar a explicar esses baixos descontos. De acordo com dados do $\mathrm{IBGE}^{16}$, os custos da construção civil nas regiões do Brasil são ordenados do menor para o maior na seguinte sequência de regiões: nordeste, centro-oeste, sul, norte e sudeste. Dessa forma, não se pode atribuir os menores descontos obtidos nas licitações no centro-oeste aos maiores custos de construção dessa região.

Dessa forma, avalia-se que pode ter havido algum impacto negativo nos descontos das obras públicas licitadas pelo DNIT na região centro-oeste devido às conexões do dirigente máximo da autarquia a políticos dessa região.

\subsubsection{Denúncias de corrupção no Ministério dos Transportes e DNIT em 2011}

Em meados de 2011, todos (sete) diretores do DNIT foram substituídos devido às denúncias de corrupção envolvendo a autarquia ${ }^{17}$. Em outras palavras, foi modificado todo o comando da repartição pública. Dessa forma, cumpre verificar o que ocorreu com o desconto obtido pelas licitações antes e depois desse ano.

Nos modelos propostos considerou-se o ano de 2010 como a variável dummy oculta para o ano de licitação, a fim de se facilitar a interpretação do efeito desse grupo de variáveis. Verificou-se que antes do escândalo de corrupção, anos de 2008 a 2010, os descontos obtidos nas licitações da autarquia eram menores do que os descontos obtidos após

\footnotetext{
${ }^{14} \mathrm{http}$ ://www1.folha.uol.com.br/poder/2011/07/945936-veja-a-cronologia-da-crise-no-ministerio-dostransportes.shtml

${ }^{15} \mathrm{http}$ ://g1.globo.com/jornal-nacional/noticia/2012/04/ex-diretor-do-dnit-acusa-abreu-e-cachoeira-deterem-armado-para-ele.html

${ }^{16} \mathrm{http}: / /$ www.ibge.gov.br/home/estatistica/indicadores/precos/sinapi/sinapi_201404comentarios.pdf

${ }^{17} \mathrm{http}$ ://www1.folha.uol.com.br/poder/2011/07/945936-veja-a-cronologia-da-crise-no-ministerio-dostransportes.shtml
} 
a troca de seus dirigentes, anos de 2011 a 2013, conforme dados da Tabela 4 - Resultados da Estimação do Modelo Econométrico. Faz-se apenas a ressalva quanto ao ano de 2007, que possui uma amostra não representativa (apenas $1 \%$ do universo dos contratos), conforme Tabela 2 - Resumo das estatísticas das variáveis.

Além disso, cumpre ressaltar outro efeito: após a troca de comando da autarquia, meados de 2011, o desconto obtido nas licitações aumentou significativamente: para o ano de 2011, o desconto foi 5,4\% superior ao ano de 2010 nos 3 modelos. No mesmo sentido, o ano de 2012 apresentou desconto 7,0\% superior ao ano de 2010 e por fim, o ano de 2013 apresentou desconto $3,6 \%$ maior que 2010 , todos significantes a $1 \%$.

Esse dado joga luz sobre outro aspecto: a alternância de poder. As constatações deste estudo confirmam os resultados obtidos por Coviello e Gagliarducci, (2010), que utilizaram um conjunto de dados de licitações sob responsabilidade de diversos prefeitos de cidades italianas para fornecer evidência empírica referente ao poder de influência desses políticos nas contratações públicas. Esses autores verificaram que no segundo mandato de um prefeito, as obras públicas eram contratadas com descontos na licitação 5,7\% inferior às obras públicas licitadas no primeiro mandato. Além disso, a concorrência dos certames foi reduzida em $11,7 \%$ no segundo mandato dos prefeitos.

No presente estudo, verificou-se que as obras públicas, logo após a troca de comando do DNIT, foram contratadas com desconto $5,4 \%$ superior às obras contratadas na gestão antiga, no mesmo sentido do estudo realizado por Coviello and Gagliarducci (2010).

Relevante ressaltar também o possível efeito da imprensa neste episódio, tendo em vista que houve uma cobertura exaustiva desse escândalo de corrupção que resultou na troca de comando da autarquia. Em outras palavras, os gestores e as empresas podem ter agido de forma mais zelosa durante esse período por causa da cobertura da imprensa e não somente porque possíveis conexões políticas se romperam com a troca de comando da autarquia. Por outro lado, o aumento de desconto não se restringiu apenas ao ano de 2011, persistindo até 2012, o que reforça a hipótese de possível rompimento de ligações políticas danosas ao interesse público, pelo menos nesse interregno. Cumpre ainda ressaltar, que essa variação no desconto das licitações pode estar relacionada ao ciclo político, no entanto, o período estudado não permite confirmar essa hipótese. 


\subsubsection{Valores doados às campanhas}

A partir dos dados da Tabela 4 - Resultados da estimação do modelo econométrico, constatou-se que no modelo 3, as variáveis que descrevem o valor doado às campanhas não são individualmente significantes para explicar o desconto obtido nas licitações de obras públicas. $\mathrm{O}$ teste $\mathrm{F}$ da hipótese conjunta de significância das 3 variáveis também indica que não se pode rejeitar a hipótese de que essas variáveis não são significantes no modelo 3, conforme Tabela 7 - Teste F valores doações.

\section{Tabela 7 - Teste F valores doações}

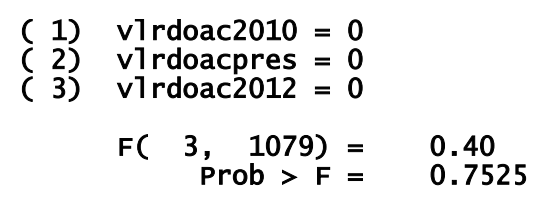

Fonte: elaboração do autor

Já no modelo 2, em que não há a presença das variáveis dummies de doações, mas apenas as variáveis que indicam os valores doados, constatou-se que apenas o valor doado às campanhas para governador, deputado e senador no ano de 2010 é significante à $10 \%$, e capaz de explicar alguma variação no desconto das obras públicas. Nesse caso, a cada 1 milhão doado, há redução no desconto da licitação no montante de $0,18 \%$. Os valores doados à campanha presidencial de 2010 e às eleições de 2012 não foram significantes no modelo 2.

Cumpre ressaltar que apesar disso, as 3 variáveis que indicam o valor doado pelas empresas se correlacionam negativamente com o desconto obtido na licitação, conforme exposto na Tabela 3 - Correlações das variáveis do modelo, o que fortalece a hipótese de algum poder explicatório dessas variáveis no desconto das licitações públicas.

Relata-se ainda limitação quanto à metodologia usada neste trabalho para mensurar os valores doados pelas empresas. Não se fez distinção entre candidatos vencedores e perdedores, exceto para as eleições presidenciais; não se distinguiu doações efetuadas para políticos de fato ligados ao DNIT e ao Ministério dos Transportes; não se separou partidos de 
governo e de oposição. Esse refinamento dos valores doados poderia tornar essa variável relevante no modelo proposto.

\subsubsection{Mudança da lei de licitações - Lei 8.666/1993 x Lei 12.462/2011}

A partir de 2012, o DNIT passou a licitar suas obras por meio da nova Lei de licitações, o Regime Diferenciado de Contratações (RDC), Lei 12.462/2011. Até então, todas as licitações seguiam a Lei 8666/1993. Os resultados dos 3 modelos, dispostos na Tabela 4 Resultados da estimação do modelo econométrico, mostram que o desconto obtido nas licitações de obras públicas foi menor no âmbito do RDC. Essa diferença entre o desconto no âmbito das Leis 12.462/2011 e 8666/1993 foi de 5,4\% em relação ao preço de referência da Administração, a um nível de significância de 1\% nos 3 modelos.

Apesar desse indicativo de possível desvantagem do RDC em relação à Lei 8666/1993, há de se considerar que o DNIT tem utilizado o RDC sob diferentes regimes de execução contratual: preço global, preço unitário e contratação integrada, ao passo que no âmbito da Lei 8666/1993 a autarquia conduziu seus contratos de obras somente por meio do regime de preços unitários. A implicação disso é que os diferentes regimes de execução carregam diferentes níveis de risco para o contratante, que por certo influenciará o desconto ofertado nas licitações. Por outro lado, esse risco é precificado pelo DNIT nos seus orçamentos de referência, neutralizando assim, suposta diferença de risco decorrente dos diferentes regimes de execução contratual. Mesmo assim, é necessária cautela para afirmar que o RDC é desvantajoso em relação à Lei 8666/1993 vis à vis, sendo necessários mais estudos sobre o tema.

\subsubsection{Local de licitação: sede do DNIT x superintendências regionais}

A Tabela 4 - Resultados da estimação do modelo econométrico indica que as licitações realizadas pela Sede do DNIT em Brasília (para obras em todo o Brasil, não só em Brasília) apresentaram maior desconto do que as licitações realizadas pelas superintendências regionais da autarquia nos estados. Essa diferença entre o desconto das licitações realizadas na sede e nas superintendências do DNIT foi de aproximadamente $1,9 \%$ em relação ao orçamento de referência para os 3 modelos.

Essa constatação é uma indicação de que as superintendências do DNIT nos estados podem estar mais propensas a cederem às ingerências políticas, visto que, conforme relatado anteriormente, os cargos públicos de comando das superintendências são em sua totalidade preenchidos por apadrinhados políticos em detrimento de indicações técnicas. Já na 
sede do DNIT em Brasília, apesar de seus dirigentes serem indicados políticos, há um maior corpo técnico, que, por hipótese, dificultaria ingerências políticas quando comparado às superintendências, estas com quadro reduzido de servidores e com autonomia para licitar obras.

\subsubsection{Demais variáveis de controle}

Discorre-se, agora, sobre as demais variáveis de controle do modelo e seus efeitos no desconto obtido pela Administração nas licitações de obras públicas. Os resultados da estimação do modelo proposto neste trabalho, dispostos na Tabela 4 - Resultados da estimação do modelo econométrico, demonstram que o desconto obtido na licitação aumenta com o número de licitantes, conforme prevê a teoria dos leilões. Além disso, o modelo captou um efeito marginal decrescente do quadrado do número de licitantes. Dessa forma, encontrouse que o número de licitantes se relaciona com o desconto obtido na licitação por meio da seguinte função quadrática: “ $1,66 \% *($ licitantes $)-0,03 \% *($ licitantes $){ }^{2}$ ”, de formato parabólico. O aumento de 1 licitante implica aumento de 1,63\% no desconto obtido pela Administração nas obras públicas. Um aumento de 10 licitantes, resulta no aumento de 13,6\% no desconto obtido pela Administração. O valor máximo dessa parábola, ou seja, o maior desconto obtido na licitação é quando há 28 participantes no certame. A partir desse número de participantes não há incremento no desconto obtido nas licitações.

O poder de explicação das variáveis grupos 2 e 3 (complexidade das obras) está associado ao fato de que quanto mais complexa é uma obra, menor será a redução de preço proporcionada pelos processos licitatórios, visto o maior risco embutido na operação. A complexidade ou especificidade das obras diminui com o aumento do número atribuído a cada grupo, ou seja, o grupo 1 refere-se a obras mais complexas e específicas (obras de implantação, duplicação e restauração rodoviária), o grupo 2 a obras de manutenção por desempenho (Crema 1 e Crema 2) e o grupo 3 àquelas de menor complexidade ou especificidade (conservação rodoviária).

A variável dummy "Lotes", que atribui valor 1 nos casos de licitação de mais de um contrato de obra no mesmo edital possui poder explicativo no modelo proposto. Tal fato se deve à lei de demanda e oferta. Se mais de uma obra é licitada ao mesmo tempo, no mesmo edital e para o mesmo número de empresas concorrentes, menor será a concorrência e menor será o desconto obtido pela Administração na licitação. 
A Tabela 4 - Resultados da estimação do modelo econométrico mostra que quando as obras são licitadas em mais de um lote no mesmo edital, o desconto obtido pela Administração é menor do que naquelas obras licitadas individualmente por edital. Essa diferença no desconto é de aproximadamente 1,5\% em relação ao preço de referência da Administração.

Testaram-se também as variáveis "aditivos" e "valor do edital", no intuito de se verificar se haveria alguma correlação com o desconto obtido na licitação. Os resultados do modelo estimado na Tabela 4 - Resultados da estimação do modelo econométrico, indicaram que não há relação significante entre essas variáveis e o desconto obtido pela Administração na licitação. Há de se mencionar que o efeito da variável "valor do edital” é em grande parte captado pela variável dummy grupo de obras, que naturalmente segrega as obras por valor, fazendo com que a variável valor do edital perca sua significância no modelo. 


\section{CONCLUSÃO}

Constatou-se a existência de viés no preço de contratação de obras públicas em favor de empresas que fazem doações às campanhas políticas. Essa conclusão é suportada por um modelo econométrico com dados de 1107 contratos de obras rodoviárias no âmbito do Departamento Nacional de Infraestrutura de Transportes (DNIT) entre os anos de 2007 e 2013, juntamente com dados de prestação de contas das eleições ocorridas nos anos de 2010 e 2012. O modelo estudado, estimado pelo método dos mínimos quadrados ordinários, em seção cruzada, é capaz de explicar $81 \%$ da variação do preço das licitações públicas de obras rodoviárias a cargo do DNIT (desconto na licitação).

A variação de preço nas licitações de obras públicas é medida por meio do desconto ofertado pelas empresas licitantes em relação ao preço de referência da Administração (preço reserva). Constatou-se que as licitações vencidas pelas empresas doadoras de campanha apresentaram desconto inferior às licitações vencidas pelas empresas não doadoras. Essa diferença de desconto é estatisticamente significativa e chega a aproximadamente $1,5 \%$ em relação ao preço de referência da Administração, em valor absoluto. Em valores relativos, licitações vencidas por empresas doadoras de campanha apresentaram desconto médio $10 \%$ menor do que o desconto médio de todas as licitações da amostra avaliada (desconto médio é de aproximadamente 16\%, conforme Tabela 2).

O desconto médio das licitações vencidas por empresas não doadoras de campanha é de $13,9 \%$, ao passo que o desconto médio das licitações vencidas por empresas não doadoras é de 20,7\%. Em outras palavras, licitações vencidas por empresas não doadoras apresentam desconto médio 50\% superior ao desconto das licitações vencidas por empresas doadoras.

Uma possível explicação para essa diferença entre os descontos observados entre licitações vencidas por empresas doadoras e não doadoras está na correlação positiva entre empresas doadoras e menor concorrência, ou seja, há menos licitantes nas licitações vencidas por empresas doadoras de campanha, constatação reforçada por dados de auditorias do Tribunal de Contas da União que indicam recorrente restrição à competitividade nas licitações do DNIT. Outra hipótese é a existência de cartel de empresas atuante nas obras públicas licitadas no âmbito do DNIT, pois o custo das empresas não possui poder explicativo relevante sobre os descontos obtidos nas licitações, o que pode ser um indício da formação de cartel. 
$\mathrm{Na}$ amostra avaliada, $66 \%$ das obras foram contratadas com empresas doadoras de campanha. Considerando que o valor somado destes editais nos 7 anos da amostra perfizeram R\$ 31 bilhões (66\% x R 47 bilhões), conclui-se que, numa situação de maior competitividade, sem o viés de empresas doadoras de campanhas, poderia haver um desconto adicional de 1,5\% em relação ao referencial da Administração nesses editais, representando, em valores absolutos, uma economia de R\$ 465 milhões (1,5\% x R 31 bilhões) para o Erário.

Neste estudo observou-se que no ano de 2011 o desconto nas licitações aumentou significativamente em relação ao ano de 2010. O desconto aumentou 5,4\% em relação ao referencial da Administração no ano de 2011; 7\% em 2012; e 3,6\% em 2013. Uma possível explicação seria a troca de comando do DNIT, decorrente de denúncias de corrupção em 2011, possivelmente levando ao rompimento de conexões políticas até então existentes. Outra hipótese seria devido à intensa cobertura do escândalo de corrupção pela imprensa que teria induzido maior zelo nas contratações públicas por parte da Administração e das empresas, aumentando assim o desconto nas licitações. Além dessas hipóteses, outra possível justificativa seria a influência do ciclo político.

Ainda sobre as ingerências políticas na Administração Pública, constatou-se, a partir dos resultados da estimativa do modelo econométrico, que as obras licitadas na região centro-oeste apresentaram o menor desconto nas licitações - no mínimo 3\% em relação ao preço de referência da Administração quando comparado com as demais regiões. Uma hipótese para essa constatação é a ligação do ex-diretor-geral do DNIT com denúncias de corrupção envolvendo essa região.

Cumpre ressaltar que este estudo se restringiu à variação de preço de obras públicas no momento do procedimento licitatório. Entretanto, auditorias do Tribunal de Contas da União têm constatado que durante a execução do contrato diversas irregularidades ocorrem: pagamento por serviços não executados; superfaturamento em termos aditivos; obras executadas com materiais de baixa qualidade; dentre outras. Dessa forma, é possível uma empresa apresentar grandes descontos na licitação, mas posteriormente auferir vantagens indevidas durante a execução do contrato. Em outras palavras, vantagens indevidas a empresas doadoras de campanha podem não só ocorrer no momento da licitação, mas também durante a execução do contrato. 
Por fim, registram-se algumas limitações do estudo ora empreendido e que poderá ser objeto de futuras pesquisas: maior detalhamento dos valores doados pelas empresas, separando as doações por candidatos vencedores e partidos; avaliação da evolução patrimonial das empresas ao longo dos anos; verificação de vantagens obtidas pelas empresas no decorrer da execução dos contratos; modelo considerando "aditivos" como variável dependente; criação de modelo que preveja a probabilidade de uma empresa sair vencedora da licitação. 


\section{BIBLIOGRAFIA}

Aggarwal, R. K.; Meschke, F.; Wang, T. Y. Corporate Political Donations: Investment or Agency? Business and Politics, v. 14, n. 1, 2012.

Ansolabehere, S.; Figueiredo, J. M.; Snyder, J. M. Why is There so Little Money in U.S. Politics? Journal of Economic Perspectives, v. 17, p. 105-130, 2003.

Boas, T. C.; Hidalgo, F. D.; Richardson, N. P. The Spoils of Victory: Campaign Donations and Government Contracts in Brazil. The Journal of Politics, v. 76, n. 02, p. 415429, 25 fev. 2014.

Bower, A. Procurement Policy And Contracting Efficiency. International Economic Review, v. 34, p. 873-901, 1993.

Brülhart, M.; Trionfetti, F. Public Expenditure, International Specialisation And Agglomeration. European Economic Review, v. 48, p. 851-881, 2004.

Charumilind, C.; Kali, R.; Wiwattanakantang, Y. Connected Lending: Thailand before the Financial Crisis The Journal of Business, 2006.

Claessensa, S.; Feijend, E.; Laeven, L. Political Connections And Preferential Access to Finance: The role of campaign contributions. Journal of Financial Economics, v. 88 , n. 3, p. 554-580, 2008.

Cole, S. Fixing Market Failures or Fixing Elections? Agricultural Credit in India. American Economic Journal: Applied Economics, v. 1, p. 219-250, 2009.

eLibrary, 2010.

Coviello, D.; Gagliarducci, S. Tenure in Office And Public Procurement. SSRN

Daly, S. P.; Nath, P. Reverse Auctions For Relationship Marketers. Industrial Marketing Management, v. 34, p. 157-166, 2005.

Dinç, I. S. Politicians and Banks: Political Influences on Government-Owned Banks in Emerging Markets. Journal of Financial Economics, v. 77, p. 453-479, 2005.

Engelbrecht-Wiggans, R.; Katok, E. Regret in Auctions: Theory and Evidence. Economic Theory, v. 33, p. 81-101, 2007.

Faccio, M. Politically Connected Firms. American Economic Review, v. 96, p. 369-386, 2006.

Faccio, M.; Masulis, R. W.; Mcconnell, J. J. Political Connections and Corporate Bailouts. Journal of Finance, v. 61, p. 2597-2635, 2006.

Fan, J. P. H.; Wong, T. J.; Zhang, T. Politically Connected CEOs, Corporate Governance, and Post-IPO Performance of China's Newly Partially Privatized Firms. Journal of Financial Economics, v. 84, p. 330-357, 2007. 
Faria, e. R.; Ferreira, M. A.; Santos, L. M. Fatores Determinantes Na Variação Dos Preços Dos Produtos Contratados Por Pregão Eletrônico. Revista de Administração Pública, v. 44, n. 6, p. 1405-1428, 2010.

Ferguson, T.; Voth, H. J. Betting on Hitler - The Value of Political Connections in Nazi Germany. Quarterly Journal of Economics, v. 123, p. 101-137, 2008.

Fisman, R. Estimating the Value of Political Connections. The American Economic Review, v. 91, n. 4, p. 1095-1102, 2001.

Goldman, e.; Rocholl, J.; So, J. Political Connections and the Allocation of Procurement Contracts. Unpublished paper, p. 1-50, 2008.

Gujarati, D. N. Econometria Básica. 4. ed. Rio de Janeio: Elsevier, 2006. v. 4.p.

Johnson, S.; Mitton, T. Cronyism and Capital Controls: Evidence from Malaysia. Journal of Financial Economics, v. 67, p. 351-382, 2003.

Khwaja, A. I.; Mian, A. Do Lenders Favor Politically Connected Firms? Rent Provision in an Emerging Financial Market. The Quarterly Journal of Economics, v. 120, p. 1371-1411, 2005.

Krieger, G.; Rodrigues, F.; Bonassa. Os Donos Do Congresso: A Farsa Na CPI Do Orçamento. 2. ed. São Paulo: Editora Ática, 1994. p. 237

Lösch, A. Combining quantitative methods and grounded theory for researching E-reverse auctions. Libri, v. 56, p. 133-144, 2006.

Mancuso, W. P. O Empresariado como Ator Político no Brasil: Balanço da Literatura e Agenda de Pesquisa. Revista de Sociologia e Política, 2007.

Mcafee, R. P.; Mcmillan, J. Bidding for Contracts: A Principal-Agent Analysis. The Rand Journal of Economics, v. 17, p. 326-338, 1986.

Mironov, M.; Zhuravskaya, E. Corruption in Procurement and Shadow Campaign Financing : Evidence from Russia. SSRN, v. 1946806, p. 1-46, 2012.

Porter, R. H.; Zona, J. D. Detection of Bid Rigging in Procurement Auctions. Journal of Political Economy, 1993.

Resnick, P.; Zeckhauser, R. Trust Among Strangers in Internet Transactions: Empirical Analysis of eBay's Reputation System. Advances in applied Economy p. 127-157, 2002.

Rumba, J.; Jasčišens, V. Public Procurement and political connections: The case of Latvia. Stockholm School of Economics in Riga, 2009. 
Samuels, D. J. Does Money Matter? Credible Commitments and Campaign Finance in New Democracies Theory and Evidence From Brazil. Comparative Politics, v. 34, p. 23-42, 2001.

Santos, M. H. de C; Machado, E. M.; Rocha, P. E. N. O Jogo Orçamentário da União: Relacões Executivo-Legislativo na Terra do Pork-Barrel. Reforma do Estado e Democracia no Brasil: Dilemas e Perspectivas, eds. Eli Diniz e Sérgio de Azevedo. Brasília: Editora da UnB, 1997. p. 83-124

Snyder, JR., J. M. Campaign Contributions as Investments: The U.S. House of Representatives, 1980-1986, Journal of Political Economy, 1990.

Svensson, J. Eight Questions About Corruption. Journal of Economic Perspectives, 2005.

Teo, T. S. H.; Lin, S.; Lai, K. Hung. Adopters and Non-Adopters of eprocurement in Singapore: An empirical study. Omega, v. 37, p. 972-987, 2009.

Tollini, H. Reforming the Budget Formulation Process in the Brazilian Congress OECD Journal on Budgeting, 2009.

White, H. A Heteroskedasticity-Consistent Covariance Matrix Estimator and a Direct Test for Heteroskedasticity. Econometrica, v. 48, p. 817-838, 1980.

Wooldridge, J. M. Introdução à Econometria - Uma Abordagem Moderna. 4. ed. São Paulo: Cengage Learning, 2013. v. 2 p. 701 


\section{APÊNDICE}

Verificação da presença de todos os pressupostos para a aplicação do método de estimação dos mínimos quadrados ordinários, em seção cruzada. A análise a seguir foi realizada para o modelo - 3, mais completo. Cumpre relatar que os modelos são bem próximos, ao ponto dessa análise ser válida para todos. Primeiramente, o modelo proposto é linear nos parâmetros, podendo ser escrito pela forma matricial: desconto $=\mathrm{BX}+\mathrm{u}$, sendo desconto a variável dependente; $\mathrm{B}$ o vetor de parâmetros; $\mathrm{X}$ o vetor de variáveis independentes; e u um erro aleatório não observável.

Em segundo, as observações do estudo representam quase a totalidade das licitações realizadas pelo DNIT entre os anos de 2007 e 2013. O ano de 2007 possui poucas observações, somente 18 , visto que o sistema informatizado do DNIT de onde os dados deste estudo foram coletados começou a vigorar plenamente a partir do ano de 2008. Além disso, ficaram de fora alguns tipos específicos de contratos, como: obras de sinalização, serviços de supervisão e projeto. Os demais tipos de obras foram incluídos na amostra, conforme especificado pelos grupos 1, 2 e 3 descritos na Tabela 1 - Descrição das variáveis do modelo.

Em terceiro lugar, cumpre verificar a normalidade dos erros, ou seja, se são normalmente distribuídos e com média zero. Para tal utilizou-se o teste Skewness e kurtosis para avaliação da normalidade dos resíduos (função sktest do Software Stata 11). O resultado contido na Tabela 8 - Pressuposto de normalidade dos resíduos da regressão demonstra que não se rejeita a hipótese de que os resíduos são normalmente distribuídos. Dessa forma, é válido o pressuposto da normalidade dos erros. Além disso, sua média é zero.

Tabela 8 - Pressuposto de normalidade dos resíduos da regressão

\begin{tabular}{|c|c|c|c|c|c|c|}
\hline \multirow[b]{2}{*}{ Variable } & \multicolumn{4}{|c|}{ Skewness/Kurtosis tests for Normality } & & \multirow{2}{*}{$\begin{array}{l}\text { joint } \\
\text { Prob>chi2 }\end{array}$} \\
\hline & obs & $\operatorname{Pr}$ (Skewness) & $\operatorname{Pr}($ Kurtosis) & $\operatorname{adj}$ & chi2(2) & \\
\hline$r$ & $1.1 \mathrm{e}+\mathrm{C}$ & 0.2263 & 0.5641 & & 1.80 & 0.4071 \\
\hline
\end{tabular}

Fonte: elaboração do autor

Verificou-se que o modelo apresentava heteroscedasticidade, conforme demonstra o teste de Breusch-Pagan (função hettest do Stata 11), Tabela 9 - Diagnóstico de 
homocedasticidade. Cumpre mencionar que a heteroscedasticidade não provoca viés ou inconsistência nos estimadores de MQO. Além disso, a medida da qualidade do ajuste, $\mathrm{R}^{2}$, também não é afetada pela heteroscedasticidade (Wooldridge, 2013).

Tabela 9 - Diagnóstico de homocedasticidade

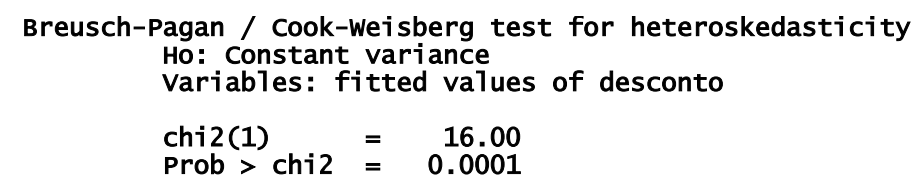

Fonte: elaboração do autor

Para correção da heteroscedasticidade, optou-se pelo método de estimação por MQO com procedimentos robustos, conforme especificado por White, (1980). Cumpre mencionar, ainda, a ausência de multicolinearidade perfeita entre as variáveis, o que possibilita a utilização do MQO. 